Revue des patrimoines

Le patrimoine monumental du comté de Nice entre France et Piémont, d'une histoire nationale à l'autre 1830-1930

Between France and Piedmont, the monuments of the County of Nice between national histories, 1830-1930

\title{
Alain Bottaro
}

\section{(2) OpenEdition}

Journals

\section{Édition électronique}

URL : https://journals.openedition.org/insitu/20293

DOI : 10.4000/insitu.20293

ISSN : 1630-7305

\section{Éditeur}

Ministère de la Culture

\section{Référence électronique}

Alain Bottaro, «Le patrimoine monumental du comté de Nice entre France et Piémont, d'une histoire nationale à l'autre 1830-1930 », In Situ [En ligne], 38 | 2019, mis en ligne le 15 février 2019, consulté le 21 septembre 2021. URL : http://journals.openedition.org/insitu/20293 ; DOI : https://doi.org/ 10.4000/insitu.20293

Ce document a été généré automatiquement le 21 septembre 2021.

\section{c) (1) $९$}

In Situ Revues des patrimoines est mis à disposition selon les termes de la licence Creative Commons Attribution - Pas d'Utilisation Commerciale - Pas de Modification 4.0 International. 


\section{Le patrimoine monumental du comté de Nice entre France et Piémont, d'une histoire nationale à l'autre 1830-1930}

Between France and Piedmont, the monuments of the County of Nice between

national histories, 1830-1930

Alain Bottaro

1 "J'ai dit au Ministre qu'il fallait occuper monumentalement le comté de Nice et la Savoie. Il y a près de Nice La Turbie qu'il faut fouiller, fouiller aussi Avenches en Savoie. Il y a de ce côté plusieurs églises très curieuses. J'en demande la note à Lasteyrie. Il y a lieu à demander de l'argent ${ }^{1} . »$

2 C'est avec cette formule-programme de 1861 que Prosper Mérimée, inspecteur des Monuments historiques de Napoléon III, prépare, au lendemain de l'annexion, l'entrée du comté de Nice dans le giron de l'administration française du patrimoine. L'enjeu politique ne lui avait pas échappé, il s'agissait d'intégrer les monuments niçois, jusque-là monuments des États sardes, dans le patrimoine français et l'histoire nationale.

3 En effet, au moment de l'émergence des premières lois et des institutions de sauvegarde $\mathrm{du}$ patrimoine monumental entre 1830 et 1860 , la France et le royaume de PiémontSardaigne élaborent de façon concomitante leur politique patrimoniale. Les édifices et les sites niçois ont eu ainsi à connaître deux administrations des Cultes et deux services des Monuments historiques du fait du transfert de souveraineté en 1860. Ces changements politiques ont eu par ailleurs pour corollaire la participation à l'illustration de deux histoires nationales, celle du Piémont d'abord puis celle de la France après 1860. 


\section{De la « Giunta di Antichità » à la commission des Monuments historiques, les premiers classements, 1832-1913}

Les Monuments historiques du Piémont s'organisent en même temps et sur le même mode que le service français. C'est la restauration de l'abbaye de Hautecombe, antique nécropole de la Maison de Savoie, décidée par le roi Charles-Félix à partir de 1828, qui donne l'impulsion de l'intervention étatique dans le domaine de la sauvegarde des monuments historiques dans le royaume de Piémont-Sardaigne. La « Giunta di Antichità e Belle Arti ", l'équivalent de la commission française des Monuments historiques, est instituée en 1832. Le dispositif est complété en 1837 par la nomination de l'architecte et archéologue royal, Carlo Promis, comme premier inspecteur des monuments d'Antiquité (« ispettore dei monumenti d'antichità dei reali Stati ») (fig. 1). Enfin, un comité royal pour les travaux historiques, la «Regia deputazione sovra gli studi di Storia patria", apparait en $1833^{3}$. L'originalité du Piémont se situe dans la sollicitation des cadres de l'Église, paroisses, curés et évêques, à faire émerger un réseau local de correspondants chargés, sous la direction du conservateur des Archives royales, du recensement, de l'étude et peut-être de la surveillance du patrimoine ancien. L'archiviste royal Luigi Nomis di Cossilla adresse dès 1831 aux curés une véritable lettre circulaire, le pendant de celle destinée au recensement des inscriptions lapidaires, les exhortant à signaler dans l'étendue de leur paroisse les monuments de l'Antiquité, tombes, sarcophages, vestiges d'édifices publics, ruines et autres ${ }^{4}$.

Figure 1

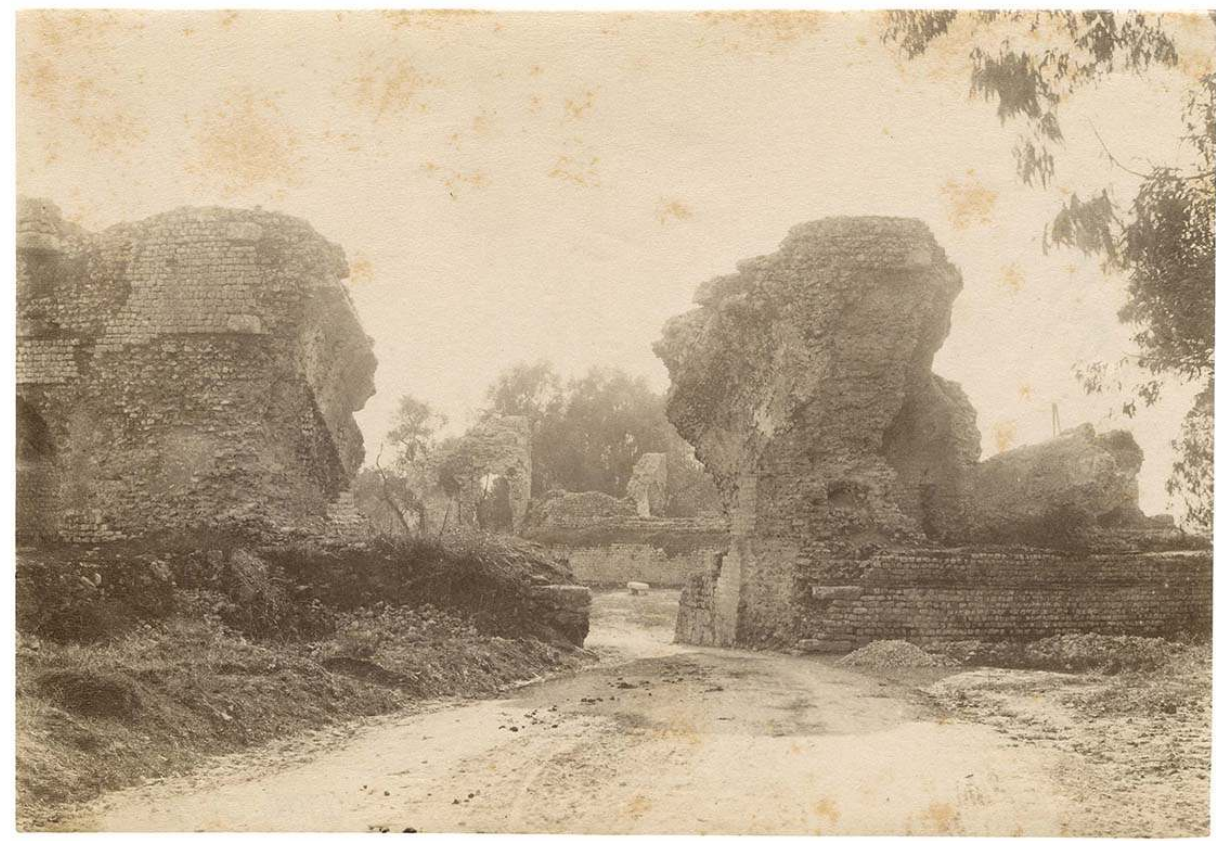

Vue de l'amphithéâtre de Cimiez à Nice, vers 1880.

Phot. anonyme, AD AM 4T 14. (c) Département des Alpes-Maritimes. 
Carlo Promis, assisté de la Giunta di Antichità e Belle Arti, a en charge la tutela, c'est-àdire l'ensemble des facettes du contrôle de l'État pour la sauvegarde. Les actions engagées dans le comté de Nice ont d'abord porté dans le champ de l'archéologie de programme avec la mise en œuvre des fouilles du site médiéval de l'ancienne cathédrale, sur la colline du Château de Nice, dès 1828. Puis, en 1859, à la veille du transfert de souveraineté à la France, le premier recensement systématique des édifices destinés au vincolo, le classement. Ce recensement est placé sous la direction de l'intendant général de la division, l'équivalent du préfet. Il prend la forme d'une tabella, un tableau dont la rédaction est confiée aux correspondants locaux. Ils retiennent quatre monuments : les édifices antiques de l'amphithéâtre de Cimiez et le trophée des Alpes de La Turbie ainsi que deux bâtiments médiévaux, la collégiale de Tende et l'église paroissiale d'Utelle. Lors de son installation, le service français confirme le recensement sarde du patrimoine antique alors que l'architecture gothique du haut-pays ne retient pas son attention.

Le classement des vestiges antiques de l'amphithéâtre de Cimiez et du trophée d'Auguste à La Turbie en $1865^{5}$ correspond à la première application dans l'arrondissement de Nice du régime français de protection des monuments historiques, cinq années après l'annexion à la France. Avant d'en examiner les modalités, il faudrait en comprendre les raisons. Elles sont de trois ordres, politique, scientifique et administratif. L'aspect politique est d'emblée perceptible dans la lettre de Prosper Mérimée. Il importe d'intégrer le patrimoine monumental du comté de Nice dans le réseau de protection du service français des Monuments historiques, le classement marque l'aboutissement d'un travail d'enquête et d'étude voulu par Mérimée. Il veut signifier l'intégration du comté de Nice dans l'aire du patrimoine français et dans l'histoire nationale. Sur le plan scientifique, les deux édifices classés se distinguent par leur exemplarité et leur monumentalité, critères prégnants à l'époque. Ils satisfont chacun à sa manière à la typologie des antiquités gallo-romaines. L'amphithéâtre de Cimiez vient se placer logiquement dans la typologie de la première liste des monuments classés en 1840 où figuraient les amphithéâtres de Nîmes, Arles et Fréjus (fig. 2). Quant au Trophée, comme unicum, il élargit la typologie des antiquités nationales. Ce sont surtout les sites les mieux connus : la Commission peut ainsi s'appuyer sur les études publiées au cours du xix ${ }^{\mathrm{e}}$ siècle. Enfin, il s'agit, sur le plan administratif, d'assurer la continuité avec le service des Monuments historiques du Piémont. En effet, dès 1828, le Génie civil était intervenu à Cimiez $^{6}$ et, à partir de 1857, à La Turbie. En outre, le premier recensement des monuments historiques de Piémont-Sardaigne, la tabella de 1859, commandée par la Giunta di Antichità e Belle Arti, avait recommandé à l'administration centrale turinoise les deux sites. Le classement de 1865 s'inscrit donc dans la continuité des actions de l'État de Piémont-Sardaigne. 
Figure 2

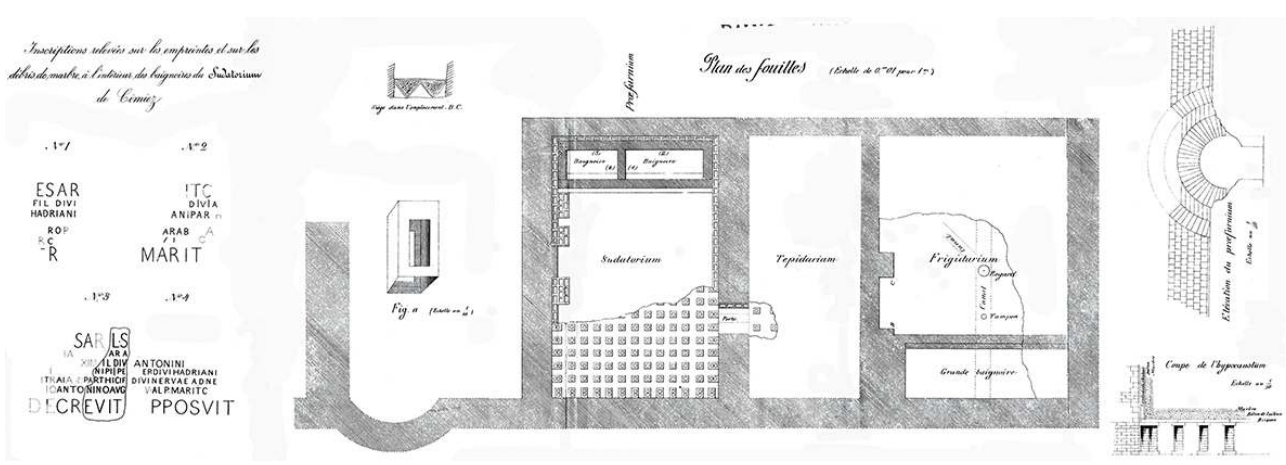

Relevé des inscriptions et plan de l'hypocauste des thermes de Cimiez par François Brun, Annales de la Société des sciences, lettres et arts des Alpes-Maritimes, 1865.

7 La continuité de l'État en matière de protection du patrimoine se révèle dans le parallélisme des organes administratifs, Giunta delle Belle Arti et commission des Monuments historiques. Plus inattendu est le rôle conféré aux sociétés savantes. À la fin de la décennie 1850, le gouvernement central de Turin cherche à organiser un réseau de correspondants locaux parmi les notabilités. Cette démarche revêt une étonnante modernité par l'acception large conférée à la notion de patrimoine historique. Ainsi, un article du journal Le Messager de Nice rapporte, le 3 janvier 1859, le projet d'une vaste enquête de recensement et de collecte de sources manuscrites, artistiques mais aussi orales :

Il est question de fonder dans chaque département et dans chaque diocèse une Société d'historiographie qui serait placée sous le double patronage de l'autorité civile et de l'autorité ecclésiastique. Cette société aurait pour but de rechercher dans les dépôts publics tous les documents historiques, biographiques, littéraires, artistiques, etc. Enfin, de recueillir toutes les traditions orales, tous les témoignages inédits et inconnus...

L'ambition des autorités piémontaises est reprise à Nice par la nouvelle administration impériale lors de l'annexion. Elle débouche sur la création, en 1861, de la Société des lettres, sciences et arts des Alpes-Maritimes ${ }^{7}$ qui rassemble sous le double patronage du préfet et de l'évêque les anciennes notabilités niçoises et les nouvelles, d'origine française, dans un projet fédérateur d'étude des arts, des sciences et de l'histoire locale. La Société des lettres devient la cheville ouvrière de l'action de l'administration des Monuments historiques au moment de son implantation à Nice. Il ne faut pas perdre de vue le contexte éminemment politique de l'annexion: Paris éprouve le besoin de légitimer et de donner corps au nouveau département des Alpes-Maritimes, fabriqué, rappelons-le, à partir de l'arrondissement de Grasse, détaché du département français du Var, et d'un nouvellement intégré, celui de Nice. La Société œuvre dans une seule direction : elle rassemble pour la première fois les notables provençaux (arrondissement de Grasse) et niçois dans un projet fusionnel fédérateur qui tend à effacer l'ancienne frontière. La lettre des nouveaux sociétaires au préfet Denis Gavini de Campile situe cette création dans son contexte politique :

Notre société née sous vos auspices, Monsieur le Préfet, a été fondée pour seconder l'influence civilisatrice de la France dans ce pays récemment annexé en y propageant le goût des études sérieuses. Nous avons voulu concourir pour notre faible part à resserrer les liens qui unissent déjà étroitement notre population à l'Empereur et à sa nouvelle Patrie ${ }^{8}$. 
9

Le succès de cette institution nouvelle, sur une terre qui n'avait guère connu de société ou d'académie, où l'érudition avait fleuri dans les travaux individuels et les collections privées, paraît résider dans le principe de l'amalgame ${ }^{9}$. Amalgame par une sphère de compétence pluridisciplinaire où les travaux historiques côtoient les études géologiques et les articles littéraires, amalgame aussi au sein de ses membres, entre Niçois «de souche » et nouveaux résidents, mais aussi entre érudits de l'arrondissement provençal de Grasse et niçois, amalgame enfin entre patrimoine national et local lors du congrès archéologique national de 1866 qui se tint à Nice.

La Société apparaît ainsi comme le correspondant privilégié de la commission des Monuments historiques dans les années qui suivent la naissance des Alpes-Maritimes. Cette situation est atypique à une époque où, dans l'ensemble des départements, le pouvoir des correspondants locaux au sein des travaux de la Commission va en s'amoindrissant au fur et à mesure de la montée en puissance des architectes des Monuments historiques. Illustrant cette évolution, l'originalité des premiers classements réside dans le rôle central joué par la Société des lettres, sciences et arts des AlpesMaritimes. En effet, tant dans la correspondance du préfet que dans les procès-verbaux de la commission des Monuments historiques elle-même, les classements de 1865 sont présentés comme l'entérinement des propositions de la Société ${ }^{10}$. Une personnalité semble se détacher, l'architecte François Brun, qui fut le premier archéologue à poser un regard scientifique sur le site de Cimiez. Dans ses études ${ }^{11}$ des bains et de l'hypocauste de Cemenelum, il se situe bien à la croisée des chemins, entre une curiosité érudite qui s'appuie sur les sources antiques, les planches gravées de Piranèse et les traités de Winckelmann, et une voie nouvelle, celle du relevé de terrain (fig. 3). 


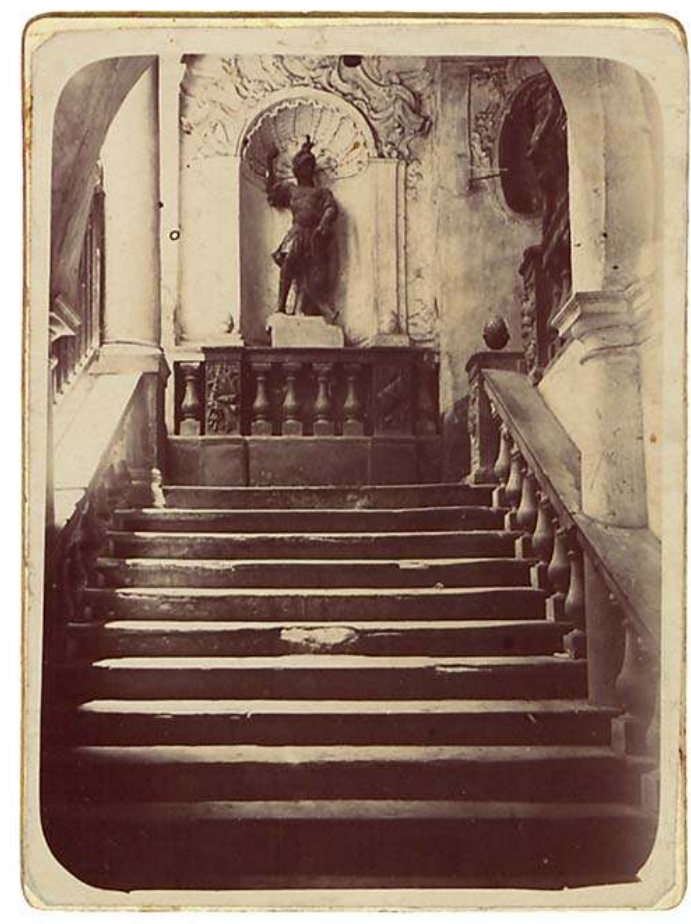

Vue intérieure du palais Lascaris à Nice, escalier d'honneur, vers 1880

Phot. anonyme, AD AM 4T 14. (c) Département des Alpes-Maritimes. dans les affaires culturelles, comme aux premiers temps de la Commission, sous la monarchie de Juillet. On retrouve, côté Niçois de souche, Auguste Carlone. Banquier, épigraphiste et chef de file du parti pro-français dans les années qui précèdent l'annexion, il assure la présidence de la jeune société. À ses côtés sont présents Xavier Eymat et Auguste Alziary de Roquefort, un Grassois, tous deux rédacteurs du Journal de Nice, l'avocat Édouard Rastoin-Brémond, le géologue Philippe Gény, l'abbé Justin (Giustiniano) Montolivo, bibliothécaire de la Ville, l'architecte François Brun. Parmi les Niçois d'adoption, on remarque le Dr Aleksander Lubanski, sommité de l'hydrothérapie, Antoine Joseph Vidal de La Blache ${ }^{12}$, inspecteur d'académie, ou encore Jean-Jacques Coulmann, ancien conseiller d'État. Si l'évêque est président d'honneur, comme le préfet, le pasteur Léon Pilatte assure en tant que membre la présence protestante. La Société est aussi conçue comme le creuset des élites du nouveau département où se mêlent pour la première fois dans une seule institution notables provençaux de l'arrondissement de Grasse et notables niçois. Parmi les fondateurs figurent ainsi le magistrat Auguste Macé, de la Société scientifique et littéraire de Cannes, et le maire de Vence Marcellin Maurel.

La Société des lettres, sciences et arts des Alpes-Maritimes atteint en 1866 le couronnement de son rayonnement culturel et de son activité politique de diffusion de la culture française avec la tenue à Nice du congrès archéologique de France, organisé par la Société française d'archéologie (SFA). Le congrès permet de voir à l'œuvre cette intégration des savants et des monuments niçois à la culture et au patrimoine français. La Société française d'archéologie, véritable fédération des sociétés archéologiques savantes 
locales, s'était structurée en corps d'inspection. Les Alpes-Maritimes ont intégré l'organisation : elles font partie de la dix-septième division qui comprend aussi le Var, les Basses-Alpes et les Hautes-Alpes, en somme, dans l'esprit des savants, les limites de l'antique province des Alpes-Maritimes au Bas-Empire. Auguste Carlone est nommé inspecteur pour les Alpes-Maritimes avec pour adjoint l'architecte Brun et l'abbé Eugène Tisserand, historien et aumônier du lycée de Nice ${ }^{13}$. La SFA a encore à sa tête, en 1866, son fondateur, l'historien de l'art Arcisse de Caumont, par ailleurs membre fondateur de la commission des Monuments historiques. La Société française d'archéologie favorise l'intégration des Niçois dans le réseau des antiquaires français. Son engagement le plus marquant, outre le choix de Nice pour le congrès de 1866, en est le prolongement fructueux voulu par Arcisse de Caumont : celui-ci veille en effet à ce que la SFA apporte son soutien à l'édition de l'étude épigraphique ${ }^{14}$ qui occupe alors Auguste Carlone en la faisant publier par son éditeur à Caen, Le Blanc-Hardel ${ }^{15}$.

En toute logique, la Société des lettres, sciences et arts s'affilie à ce réseau national et en accueille le congrès en 1866. Son programme mélange les communications sur les monuments locaux et celles sur des sujets extérieurs: le président Arcisse de Caumont brosse un tableau général des études archéologiques en France puis suivent les présentations, entre autres, des sites locaux récemment classés de Cimiez et La Turbie, mais aussi des monastères de Saint-Pons et de Lérins. Sont également présentées une communication sur les tours à signaux des littoraux français et une autre sur les chapelles médiévales du Roussillon. Une « audace » stylistique a ponctué les travaux : les membres niçois invitent leurs confrères à visiter un des hauts lieux du baroque niçois, le palais Lascaris :

Les membres du congrès... se sont immédiatement transportés à Nice, à l'habitation de M.Colombo, président du tribunal de commerce, qui les a accueillis de la manière la plus gracieuse. Cette maison, située rue Droite, $\mathrm{n}^{\circ} 15$, est un ancien palais de la famille Lascari [sic]. Le bouclier de la statue de guerrier qui décore l'escalier est un écu écartelé, au premier et au quatrième quartier... Cette statue, dans le style du $\mathrm{xVI}^{\mathrm{e}}$ siècle, représente un des membres de la famille des Lascaris, un des membres sans doute de la famille des Lascaris de Vintimille (fig. 4). La façade rappelle les palais génois du XVII siècle; l'étage noble est décoré de fresques dues aux frères Carlone... Les caryatides de l'alcôve sont d'un assez joli style ${ }^{16}$. 


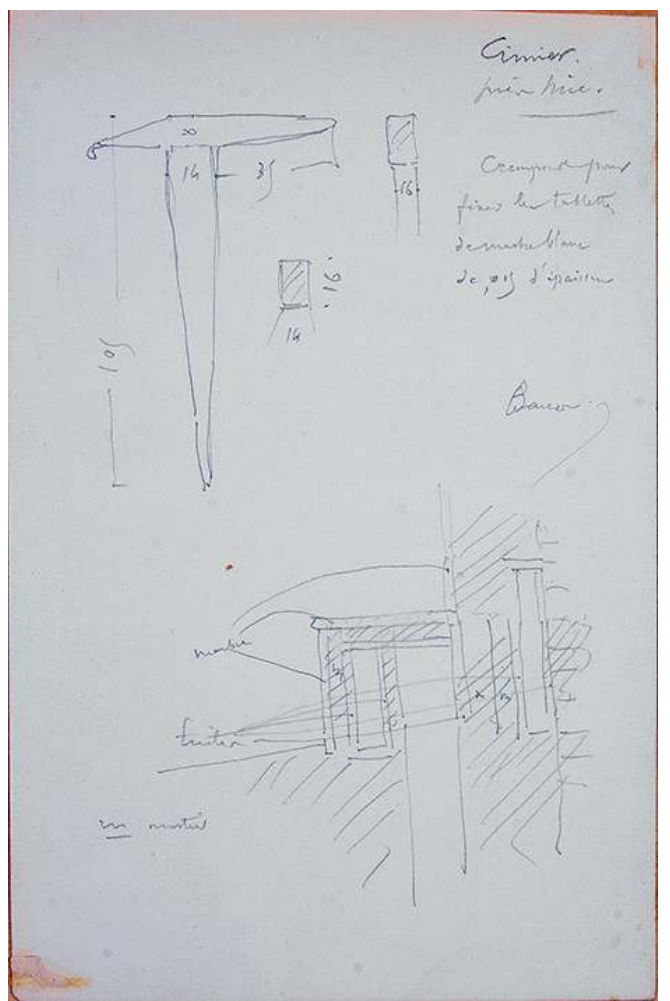

Croquis de détail de crampon et de fixation à l'amphithéâtre de Cimiez à Nice, Victor Ruprich-Robert, vers 1871, musée d'Orsay.

Phot. Patrice Schmidt. @ Ministère de la Culture (France) - Musée d'Orsay - diffusion RMN.

À partir de 1898, un autre protagoniste apparaît dans le champ de l'érudition scientifique. Le professeur Henri Sappia donne une veine militante à l'étude du patrimoine culturel niçois en fondant Nice historique, revue scientifique qu'il utilise pour la publication de sources historiques littéraires et d'articles historiographiques. Il est rejoint dans cette quête des racines et de l'identité culturelle par des notables sensibles aux débats entourant le régionalisme et au prestige de l'entreprise félibréenne ${ }^{17}$. Le groupe fonde en 1904 l'Acadèmia Nissarda ${ }^{18}$. Près de soixante années après la création «française » de la Société des sciences, lettres et arts des Alpes-Maritimes, une société savante réunit des Niçois de souche et se pose en promoteur de l'identité culturelle niçoise. Son présidentfondateur, le Dr Alexandre Barety, est le premier à entreprendre à Nice un inventaire du patrimoine campanaire.

Les premières décennies du régime français offrent un bilan contrasté: logiques et éminemment symboliques, les classements de Cimiez et de La Turbie correspondent bien à la volonté des Monuments historiques français de marquer leur territoire après l'annexion. Cependant, le service des Monuments historiques ne prend en compte que lentement le patrimoine de l'ancien comté de Nice: en 1914, seulement onze édifices bénéficient du classement, deux édicules (une croix de chemin et une colonne commémorative) et quinze monuments ayant une dimension architecturale. Les types se rattachant aux thématiques nationales bien connues, l'architecture militaire comme le fort du mont Alban à Nice en $1909^{19}$. Autre thématique classique, le souvenir historique. Dans cette catégorie on trouve la colonne commémorative du passage du pape Pie VII, rue 
de France à Nice, en $1906^{20}$. L'architecture médiévale fait une timide apparition avec la croix de chemin de Cimiez, classée en 1903, le clocher roman d'Isola ${ }^{21}$ et l'église SaintÉtienne de Saint-Étienne-de-Tinée ${ }^{22}$ en 1908 et la Madone del Poggio à Saorge ${ }^{23}$ en 1913 (fig. 5).

Figure 5

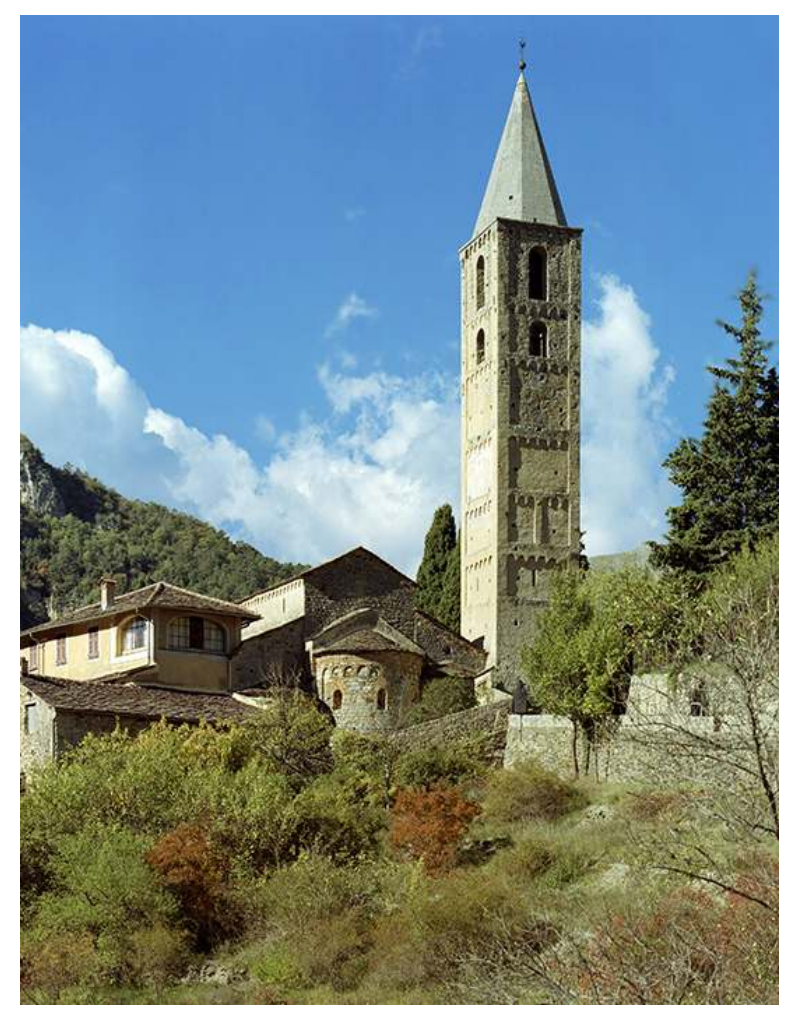

Vue de la Madone del Poggio à Saorge.

Phot. Michel Graniou. ( ) Département des Alpes-Maritimes.

Par ailleurs, dans l'arrondissement de Nice, la limite chronologique des monuments tend à s'étendre vers la période baroque à la suite de la suppression du régime concordataire, en 1905, qui entraîne le transfert d'un patrimoine immobilier de l'administration des Cultes vers les Monuments historiques. La cathédrale Sainte-Réparate ${ }^{24}$ (fig. 6) et l'abbaye de Saint-Pons ${ }^{25}$ sont ainsi classées en 1906 et 1913, rares exemples baroques protégés à cette époque. 


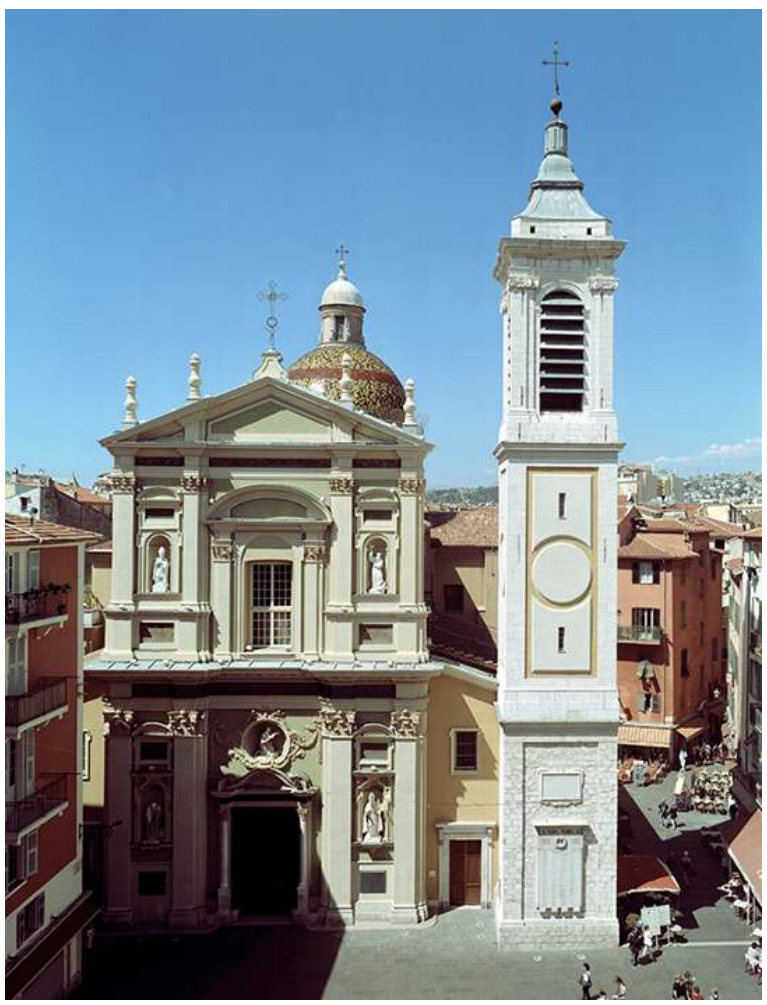

Vue de la cathédrale Sainte-Réparate à Nice.

Phot. Michel Graniou. (c) Département des Alpes-Maritimes.

Enfin, on remarque deux édifices atypiques dans cette liste : la croix de marbre ${ }^{26}$ à Nice érigée en 1568 dans le quartier éponyme et la fontaine publique Renaissance de Contes ${ }^{27}$ dont la construction remonte à 1587. Certes, la croix niçoise fait partie des souvenirs historiques, le toit de tuiles vernissées qui la protège témoigne de l'attachement des Niçois au monument, mais ces deux classements semblent néanmoins obéir à une logique scientifique d'ouverture de la protection à des formes locales de la Renaissance. La première loi de 1887 sur les monuments historiques ne semble pas avoir concouru à une augmentation du nombre des édifices classés. En fait, leur relative rareté ne doit pas occulter le dynamisme du recensement mené par les correspondants locaux de la Commission, ce que tendrait à démontrer la dispersion géographique des édifices protégés sur le territoire départemental. De même, une étude statistique sur le plan national serait nécessaire pour évaluer la situation de la protection du patrimoine dans les Alpes-Maritimes. Cependant, le petit nombre d'élus et, en creux, le nombre d'exclus, en particulier l'ensemble du patrimoine médiéval (hors la chapelle des Trinitaires de Saint-Étienne et la Madone del Poggio et le clocher d'Isola), renvoient au regard porté par le réseau des Monuments historiques français. Deux cas d'école mettent en relief les conséquences du transfert de souveraineté sur le patrimoine : l'église paroissiale SaintVéran d'Utelle (XII siècle) (fig. 7) et la collégiale de Tende ( $\mathrm{xI}^{\mathrm{e}}$ siècle) figurent dans le premier recensement monumental systématique de l'administration piémontaise en 1859. Dans un premier temps, elles disparaissent des listes françaises, et il faut attendre 1949 pour Tende ${ }^{28}$ et 1963 pour Utelle ${ }^{29}$ pour qu'elles soient classées au titre des monuments historiques. 
Figure 7

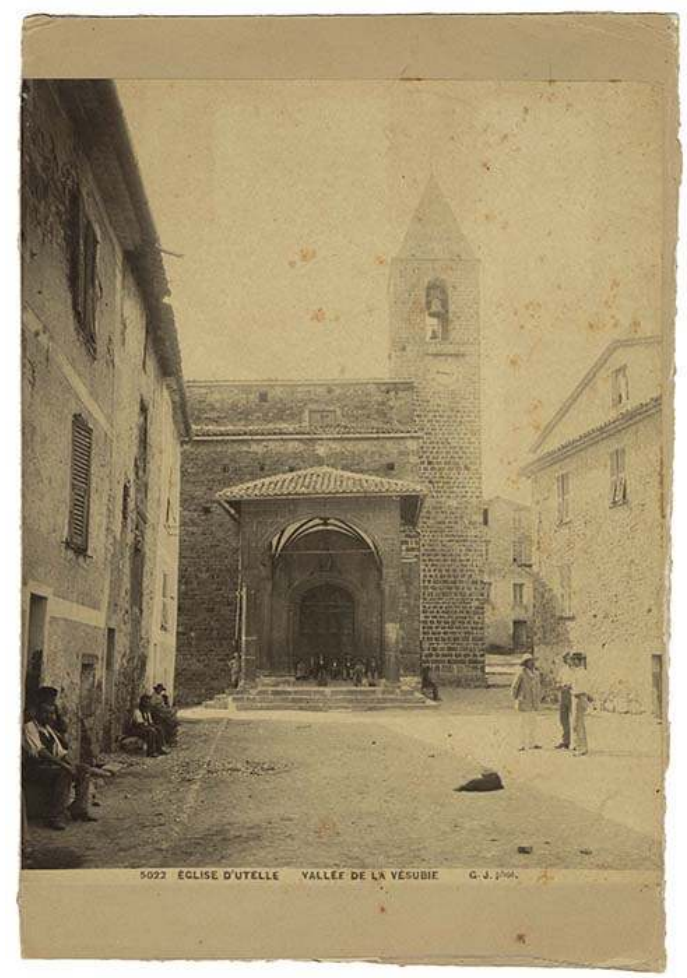

Vue de l'église Saint-Véran à Utelle, vers 1900.

Phot. Jean Gilletta, AD AM 4T 16. @ Département des Alpes-Maritimes.

Certes, le choix des recenseurs subit le filtre de critères nationaux, mais la question de la prise en compte des spécificités locales mérite d'être posée. L'intégration des édifices remarquables du comté de Nice dans le patrimoine monumental français correspond à une problématique complexe qui revêt trois aspects principaux : l'implantation à Nice du réseau des Monuments historiques, l'enjeu architectural avec la mise en œuvre de la doctrine française de la restauration et l'enjeu politique d'un patrimoine tiraillé entre deux mémoires nationales. Le comté de Nice est dans une large mesure terra incognita pour le service français en 1860 : une profusion d'édifices baroques peu compris, à tel point que la démolition du couvent des Dominicains est ordonnée malgré la façade de Benedetto Alfieri, un des architectes majeurs du baroque piémontais de la seconde moitié du XVIII ${ }^{e}$ siècle (fig. 8). Autres singularités, le comté de Nice présente un patrimoine médiéval spécifique, un clergé réputé ultramontain avec lequel il faut composer, des élites formées dans la Péninsule : seuls les vestiges antiques offrent un terrain connu. 


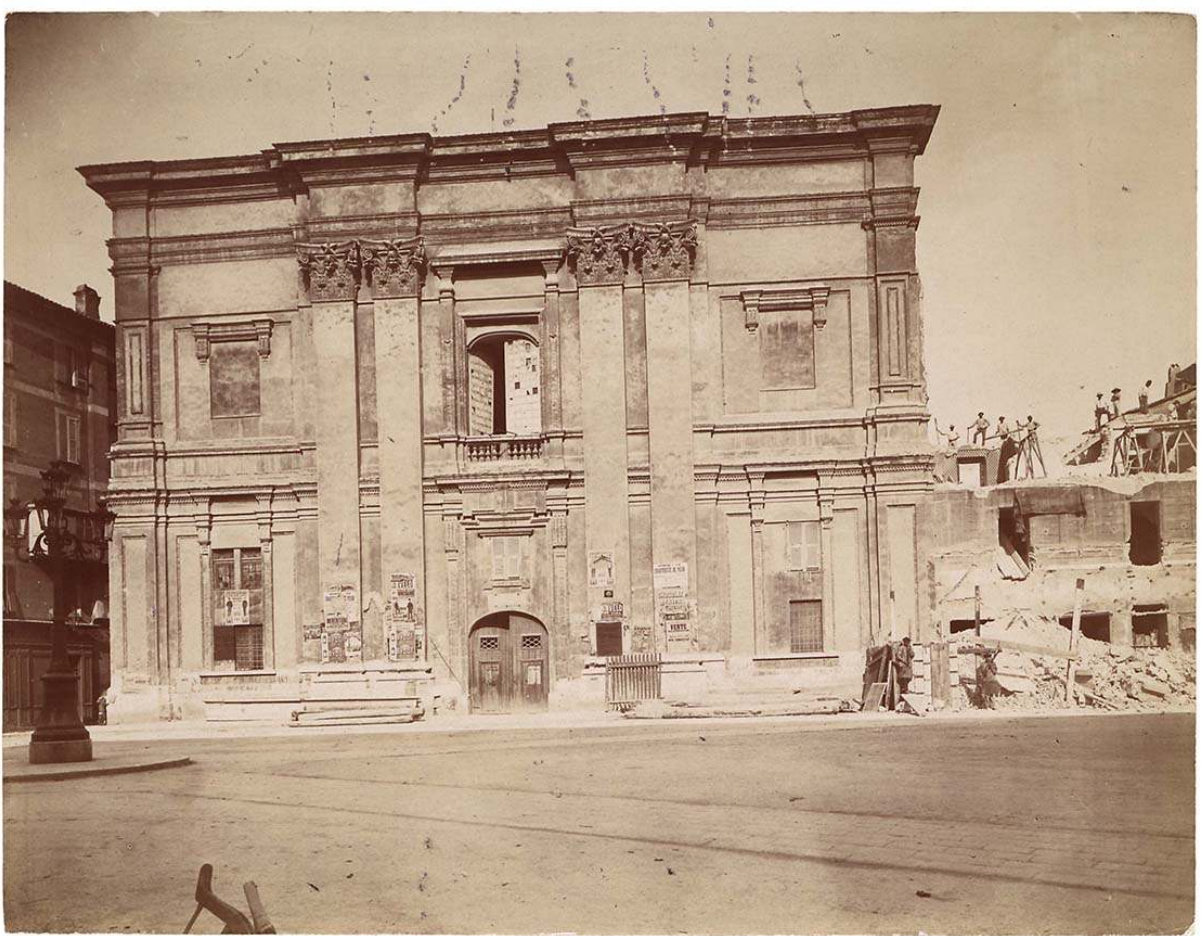

\section{De la consolidation à la restitution, la question des doctrines de restauration}

Un second aspect du rattachement du patrimoine niçois s'inscrit cette fois dans un temps long, celui des tendances de fond des doctrines de restauration. L'arrivée des architectes dits "diocésains » à Nice marque en effet l'extension à un ancien territoire piémontais des principes de l'école de Viollet-le-Duc. Eugène Viollet-le-Duc, "patron» des architectes diocésains, vient en visite d'inspection en 1863, une prise de possession en quelque sorte, alors que son disciple Victor François Sabatier ${ }^{30}$ avait été nommé architecte diocésain de Nice dès le 17 mars $1861^{31}$. Très apprécié du maitre, ce dernier avait évincé son concurrent Jean Dominique dit La Liberté qui, pour appuyer sa candidature, avait fait valoir des recherches sur l'architecture dans le Midi de la France et en Italie du Nord. Victor Sabatier est en fait issu du sérail de deux grandes institutions en charge du patrimoine monumental dans la France de la Restauration et du Second Empire, le conseil des Bâtiments civils et le service des Édifices diocésains. Élève de l'École des beaux-arts, il débute en 1844 sur le chantier de restauration de l'église SainteGeneviève (Paris, actuel Panthéon) avant d'entrer dans l'agence d'Hector Lefuel, l'architecte de Napoléon III au palais du Louvre. Sabatier bâtit sa carrière niçoise sur le prestige que confère le poste de « diocésain » : architecte, historien de l'art, expert dans les anciens modes de construction et dans les styles, il devient dans la Nice impériale la référence de l'école historiciste et de l'éclectisme architectural alors en vogue. Ainsi, de la 
conservation des monuments, il passe, comme c'est souvent le cas à l'époque, à la conception de projets tant publics que privés, au service de la clientèle aristocratique des hivernants. Il cumule rapidement la fonction d'architecte diocésain avec celle d'architecte du département, tout en dirigeant sa propre agence. Pour ne citer que sa plus fameuse création conservée, le vicomte Georges Vigier lui commande sa villa du mont Boron en gothique vénitien, réplique de la $\mathrm{Ca}^{\prime}$ d'Oro. Curieusement, dans les AlpesMaritimes, la commission des Monuments historiques ne fait pas appel à l'architecte diocésain. Le nouveau département apparaît comme un enjeu politique qui justifie un traitement particulier, de choix dirons-nous. La correspondance de Mérimée révèle que les inspections à Cimiez, à La Turbie et dans les églises niçoises sont menées par les «patrons» Viollet-le-Duc et Émile Boeswillwald. À cela il faut ajouter l'influence omniprésente que Mérimée en personne exerce depuis Cannes, où il passe ses hivers depuis 1858.

Mais l'arrivée des architectes français en 1861 ne se fait pas sur un territoire vierge : on a restauré en Piémont et dans le comté de Nice avant 1860, ou plutôt on a consolidé. En effet, à cette époque, l'inspecteur des Monuments Carlo Promis dirige lui-même comme architecte les grands chantiers de restauration voulus par les souverains. Mais dans les provinces, c'est le corps du Génie civil qui intervient sur les monuments, sous le contrôle des intendants généraux. Contrairement au contexte français, la plupart des chantiers, en Piémont, sont l'affaire des ingénieurs et non des architectes. Il en découle une conception doctrinale sensiblement différente, née à la fois du savoir des ingénieurs, plus constructeurs qu'architectes, et de la rareté des crédits à la disposition de la Giunta. La doctrine piémontaise, si doctrine constituée il y a, se borne à la consolidation, quand l'école de Viollet-le-Duc prône la restauration idéale.

21 La restauration du trophée d'Auguste de La Turbie offre l'exemple du passage d'une doctrine de restauration à l'autre. En effet, le chantier, commencé en 1857 sous l'administration sarde, ne s'achève que dans les années 1910. Urbano Rattazzi, ministre de l'Intérieur, ordonne en 1857 la consolidation du Trophée et énonce le principe qui doit présider au choix du parti de restauration :

le soussigné [ministre] s'adresse à M. l'Intendant général de Nice et le prie d'inviter M. l'Ingénieur de cette province à se rendre sur les lieux afin de reconnaître l'état précis dudit Monument d'Auguste et la nature des réparations à y effectuer et d'en faire un rapport à l'attention du Ministre, accompagné d'une estimation du coût des travaux. Ces travaux, cela lui est clairement notifié, doivent tendre uniquement à empêcher la ruine ou la dégradation progressive dudit Monument, le maintenir dans le statu quo [souligné dans le texte] en l'état et non pas à lui rendre sa forme antique ${ }^{32}$.

Sur le rapport de l'ingénieur en chef de la province, les travaux sont affermés par l'État au maître maçon Carlo Francesco en février 1859. «Dans le tracé du mur d'enceinte du Trophée d'Auguste que l'on veut réparer, il est reconnu que le meilleur parti à adopter est tel qu'il est dessiné en rouge dans le dessin annexés3 ${ }^{33}$ » (fig. 9). 


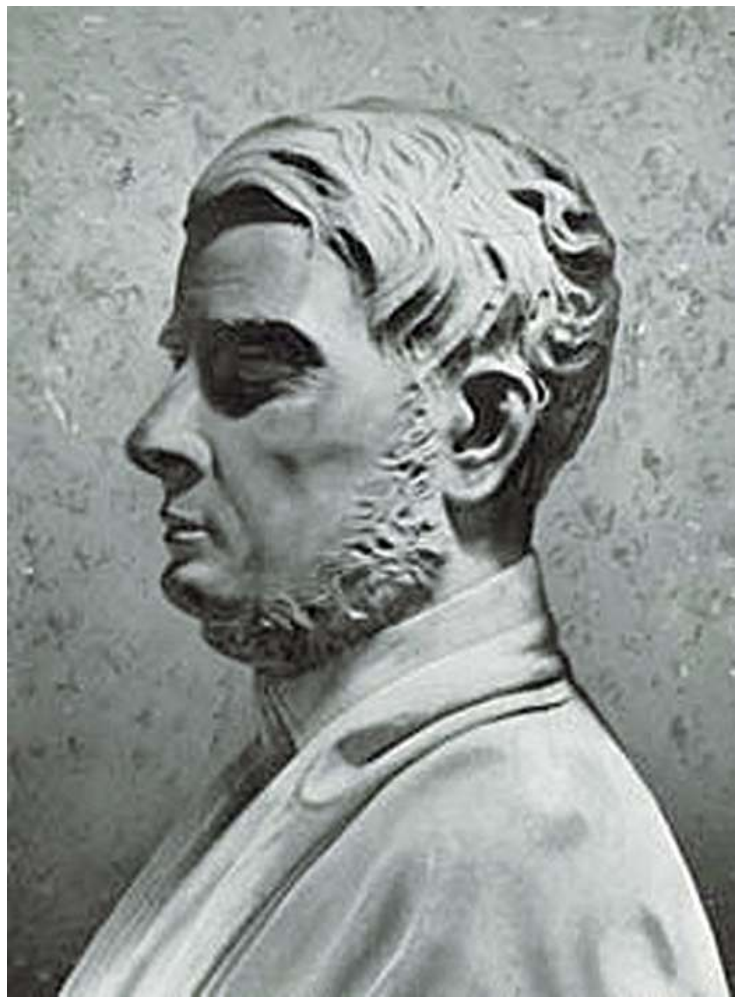

Carlo Promis, bas-relief XIXe s., Istituto politecnico di Torino

Phot. Alain Bottaro. @ Politecnico di Torino/Alain Bottaro.

Soixante ans plus tard, en, 1924, alors que le parti de restauration s'est clairement engagé dans la voie de la restitution de l'antique, la commission des Monuments historiques continue à exiger le maintien de ce qui, désormais, n'est plus que la «trace médiévale ${ }^{34}$ ». La ligne directive tracée par Urbano Rattazzi pour le Trophée a valeur de manifeste une fois replacée dans les intenses débats doctrinaux de l'époque. Elle semble faire écho à la maxime formulée en 1883 par Camillo Boito, figure tutélaire de la conservation du patrimoine en Italie : «Les monuments architecturaux, lorsqu'il a été incontestablement démontré qu'il est nécessaire d'y porter la main, doivent être plutôt consolidés que réparés et plutôt réparés que restaurés, en évitant avec le plus grand soin d'y apporter des adjonctions et des rénovations ${ }^{35}$.» L'originalité de la pensée de Boito vient de sa formation personnelle et de sa double carrière de romancier ${ }^{36}$ et d'architecte. Il aborde le monument ancien comme un manuscrit. Il ne se prive pas d'aller au-delà de la conservation, pourvu qu'elle soit littérale ou philologique: "Que diriez-vous d'un antiquaire qui, ayant découvert un nouveau manuscrit de Dante ou de Pétrarque, mutilé et en grande partie illisible, s'emploierait à en remplir de son propre chef, astucieusement et avec science, les lacunes, de manière à rendre ses adjonctions impossibles ou très difficiles à distinguer ? ?37 " $^{37}$

24 L'autre site du patrimoine antique est l'amphithéâtre de Cimiez. L'intervention des architectes officiels se fait très progressivement. Nous savons par une lettre de Mérimée à Boeswillwald que le nouvel inspecteur des Monuments historiques est en tournée en 1863 à Cimiez et dans les églises de Nice ${ }^{38}$. Le classement de l'amphithéâtre n'a pas d'effet tangible immédiat puisqu'il ne semble pas que des travaux de restauration soient 
survenus avant le chantier de Jean Camille Formigé en 1901 ; tout au plus peut-on repérer en 1874 la commande à l'architecte de la Ville, François Aune, du dégagement de l'édifice envahi par la végétation ${ }^{39}$ (fig. 10).

Figure 10

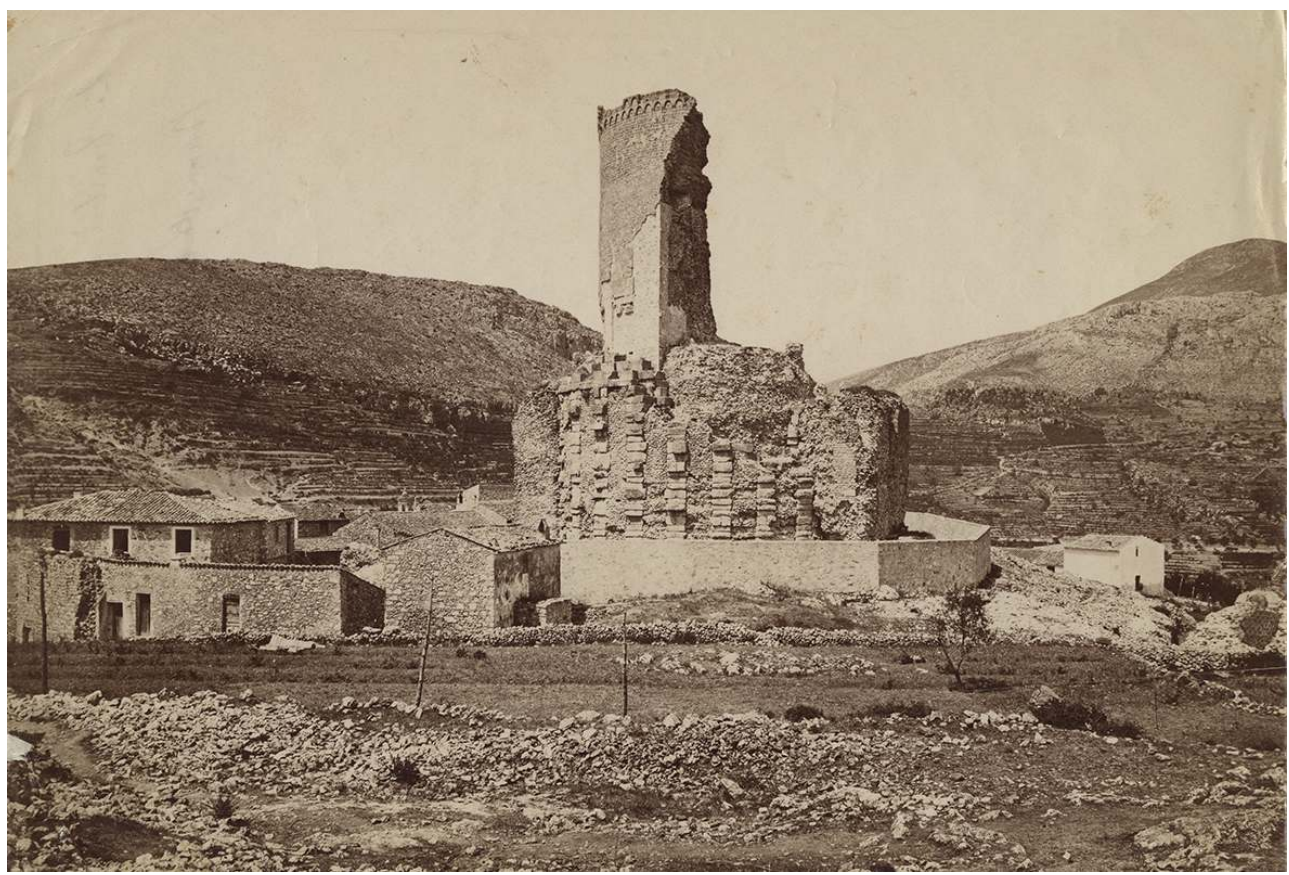

Vue du trophée des Alpes à La Turbie, vers 1870.

Phot. anonyme, AD AM 4T 16. (c) Département des Alpes-Maritimes.

\section{D'une histoire nationale à l'autre}

La similitude des créations institutionnelles de part et d'autre des Alpes pour la conservation des Monuments historiques ne doit pas occulter les différences profondes entre les deux États dans leurs motivations politiques. Si l'un se construit une histoire nationale, l'autre hésite entre culte dynastique et histoire nationale. Cette différence renvoie à l'état d'avancement de l'État-nation qui sous-tend les histoires nationales. L'essor de l'archéologie sous Napoléon III, les fouilles du site d'Alésia ou la création du musée des Antiquités celtiques et gallo-romaines sont à replacer dans le contexte d'une fondation de l'histoire de la nation française, dans laquelle les Gaulois se voient promus au rang de peuple fondateur et d'ancêtres de tous les Français. Si les racines de la France se perdent volontiers dans la nuit des temps celtes, l'Italie demeure encore, avant 1861, une réalité géographique morcelée entre différents États. Le Piémont et ses souverains n'ont pris la tête du Risorgimento qu'après bien des réticences, surmontées par le pouvoir de conviction et l'habileté politique de Cavour. Jusqu'aux années 1856-1858, la cour de Turin poursuit sa politique traditionnelle d'accroissement territorial à ses pourtours, fûtce au détriment de l'Autriche en Lombardie. L'État piémontais est encore un État dynastique gouvernant un ensemble de territoires réunis au cours de l'histoire sous le sceptre des Savoie. La fidélité dynastique cimente cette entité protéiforme, dénommée indistinctement États de la Maison de Savoie, Piémont-Sardaigne ou États sardes. La conservation des Monuments historiques et l'archéologie en Piémont durant la période 
1830-1860 relèvent bien du culte dynastique. L'abandon de la Savoie et de Nice au profit de la construction unitaire italienne, à partir de 1859, correspond à un tournant idéologique. Ce n'est qu'à partir de la fondation du royaume d'Italie, en 1861, que s'esquisse une histoire nationale italienne car si l'État italien était fondé, il restait à trouver la nation ${ }^{40}$. À ce grand projet d'écriture d'une histoire nationale répond la boulimie de projets d'édifices publics relevant d'une architecture nationale, un projet artistico-politique nouveau sur le sol italien et historiciste dans son expression, puisant ses formes dans le passé médiéval des indépendances communales. L'étude et la conservation des monuments anciens entrent alors dans cette volonté de dégager les caractères nationaux et de fonder un style national. Il est donc plus pertinent d'interpréter l'annexion de 1860 à Nice non pas comme le glissement d'une histoire nationale à l'autre mais d'un culte dynastique à une histoire nationale. Côté français, l'intégration du patrimoine niçois était d'autant plus urgente qu'une lecture nationale de l'histoire était en train de se construire de l'autre côté des Alpes.

En Piémont, le souverain est l'initiateur d'un service des Monuments historiques dont les motivations premières sont politiques. En effet, de manière concomitante sont lancés dès la fin de la décennie 1820 les chantiers de restauration et de fouilles des grands sites dynastiques de la Maison de Savoie. L'abbaye de Hautecombe, qui abrite la première nécropole des ancêtres en Savoie, fait l'objet des attentions de l'État. Elle devient un des lieux du culte dynastique (avec la basilique de Superga) à tel point que, lors de l'annexion de la Savoie à la France en 1860, le traité de Turin lui confère expressément un statut particulier de quasi-extraterritorialité. Par dérogation au régime du concordat régissant les rapports entre les Églises et l'État français, l'abbaye demeure dans le giron du domaine privé du souverain du Piémont qui y maintient son droit de patronage. Il se manifeste par la reconnaissance d'une fondation pieuse instituée par Charles-Félix et destinée à l'entretien d'une congrégation religieuse et par le maintien de la nomination de l'abbé de Hautecombe par le chef de la Maison de Savoie. En revanche, le roi s'engage à reconnaître l'autorité du service français des Monuments historiques pour la conservation des édifices ${ }^{41}$. Les premières fouilles archéologiques sur le site de l'ancien château de Nice inaugurent la série des chantiers dynastiques en 1827. Interrompues peu après, elles sont relancées en 1859, à la veille de l'annexion, sur ordre de Victor-Emmanuel II. L'ancien château ducal est attaché au souvenir de la jeunesse du duc Emmanuel-Philibert, restaurateur de l'unité du royaume à partir de la bataille de Saint-Quentin, en 1557. Les fouilles portent sur les traces du XvI ${ }^{\mathrm{e}}$ siècle, et de manière explicite sur le tombeau de la duchesse Béatrice de Portugal, épouse du duc Charles III et mère d'Emmanuel-Philibert, dont les sources littéraires situent la sépulture dans l'ancienne cathédrale, englobée dans l'enceinte du château ${ }^{42}$. L'entreprise patrimoniale de la Maison de Savoie se situe dans le contexte de la restauration de l'ordre politique ancien, après son renversement par la Révolution française. Le retour sur la tombe des ancêtres n'est pas sans rappeler les exhumations et les monuments commémoratifs commandés par les Bourbons en France, censés refonder dans l'expiation l'union séculaire de la dynastie légitime avec son peuple 43. À Nice et en Savoie, les fouilles et les restaurations des sites royaux répondent aussi au désir d'affirmer une souveraineté contestée sur les provinces un moment perdues et cela, à la veille de la signature du traité de Turin. La tabella de recensement de 1859 se situe elle aussi dans cette entreprise patrimoniale: avec les vestiges de l'antiquité romaine de Cimiez et de La Turbie, les églises d'Utelle et de Tende ont été retenues pour leur ancienneté et leur caractère précieux comme œuvres du Moyen Âge ${ }^{44}$. Il est nécessaire de 
resituer le climat idéologique dans lequel les fonctionnaires rédacteurs de la tabella évoluent. Au cours du XIX ${ }^{\mathrm{e}}$ siècle, en Italie, la question des styles et l'intérêt particulier accordé aux édifices médiévaux et renaissants dans l'approche du patrimoine revêtent une dimension politique qui dépasse l'histoire de l'art. En effet, dans le cadre du Risorgimento politique, une lecture idéologique des styles prétend contribuer à la construction de la nouvelle Italie : dès la fondation du royaume unitaire en 1861, le jeune État se cherche un style national capable de dépasser les anciennes diversités régionales ${ }^{45}$. Ce style nouveau, le style umbertino officiel, censé incarner la nouvelle Italie, s'observe dans les programmes décoratifs historicistes inspirés du Moyen Âge et de la Renaissance, l'un comme l'autre incarnant l'âge d'or de l'histoire italienne. En Piémont, le succès du revival gothique entre 1815 et 1860 a ouvert la voie à la lecture idéologique des styles. Dans la perspective de la restauration politique des anciennes dynasties régnantes, un style troubadour tend à exalter le retour à l'ordre traditionnel qui identifie dans une féodalité et un Moyen Âge idéalisés ses racines et sa légitimitée ${ }^{46}$.

Enfin, la restauration de la façade de l'église du sanctuaire de Cimiez, en 1845, d'initiative privée, prend le contre-pied de la doctrine minimaliste de la consolidation en réalisant une restitution idéale, typique du néogothique albertino piémontais. Elle serait aussi à interpréter à l'aune des restaurations idéologiques des monuments gothiques en Piémont. Notre-Dame de Cimiez, église du couvent des récollets, est à la fois le grand sanctuaire niçois extra-muros et le lieu traditionnel des rassemblements populaires des festins. La façade du sanctuaire médiéval est fortement dégradée au début du xix ${ }^{\mathrm{e}}$ siècle. Une restauration, présentée comme une restitution de l'état d'origine, est entreprise à l'initiative d'un commanditaire membre de l'aristocratie locale. Une appréciation postérieure d'une dizaine d'années aux travaux nous renseigne sur la manière dont ils ont été jugés par les contemporains :

Mais la façade du temple, qui bientôt s'offre de front au visiteur et le distrait de douces pensées vagabondes, attire sur elle toute l'attention. Elle annonce la majesté de ce Dieu qui habite dans cet édifice sacré et la vénération de cette Vierge qui reçoit ici les vœux et les hommages des fidèles. Son style gothique correspond au dessin primitif de l'église; et même si on la voit entièrement neuve, elle n'en suggère pas moins l'idée de la vénérable antiquité de ce temple. On la découvre surmontée de quatre clochetons au-dessus desquels s'élève une croix majestueuse. Au centre de la façade il y a un pinacle [guglia] qui soutient également le signe de la rédemption et culmine au-dessus des frondaisons qui lui font face ${ }^{47}$. contre l'édifice ancien, en ajout rappelant davantage le style troubadour que le gothique. Mais il faudrait réévaluer les intentions de son auteur et de ses commanditaires : loin de relever d'une simple adhésion à la mode historiciste du moment, il correspondrait plutôt pour ces aristocrates de la Restauration à une volonté de montrer le Piémont éternel, c'est-à-dire celui des temps féodaux et des liens personnels de fidélité et de service à la Maison de Savoie. Le décor peut être à la mode du moment tout en étant investi d'une charge idéologique forte. Mieux encore, on peut discerner l'intention, chez Cais de Pierlas, d'un rappel, sur le mode pittoresque, d'éléments architecturaux du Piémont. Ainsi, le couronnement par de hauts clochetons et pinacle n'est pas sans rappeler le programme décoratif des hauts pinacles de l'abbatiale de Sant'Antonio di Ranverso en Val di Susa (fig. 11, fig. 12). 
Figure 11

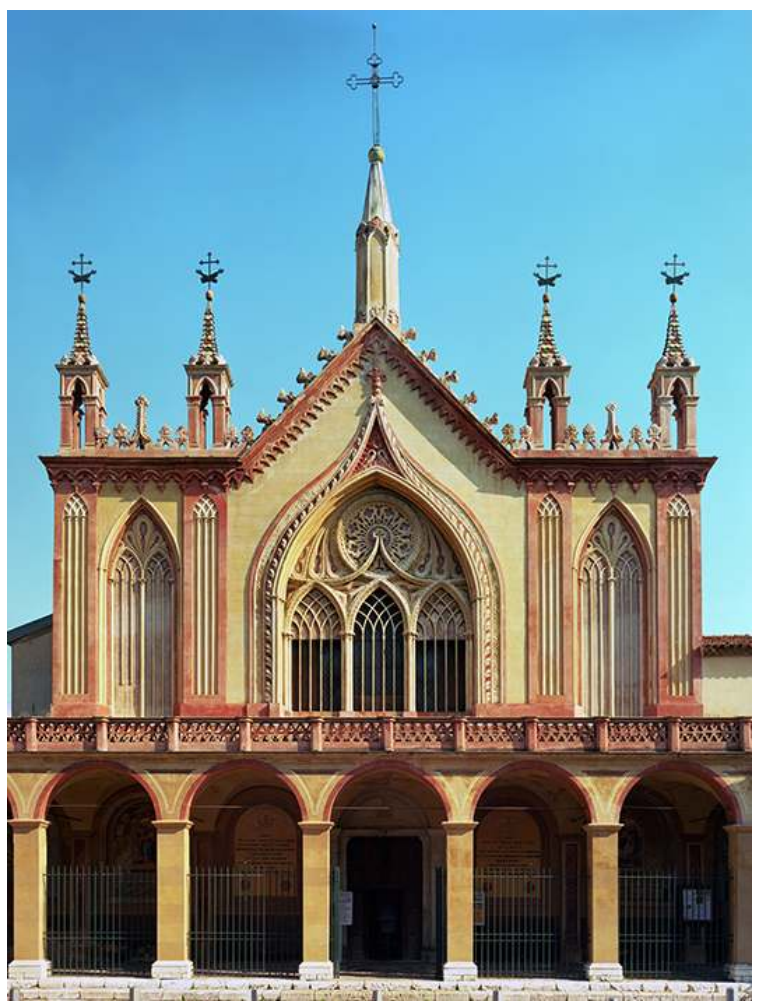

Vue de Notre-Dame de Cimiez à Nice.

Phot. Michel Graniou. @ Département des Alpes-Maritimes. 


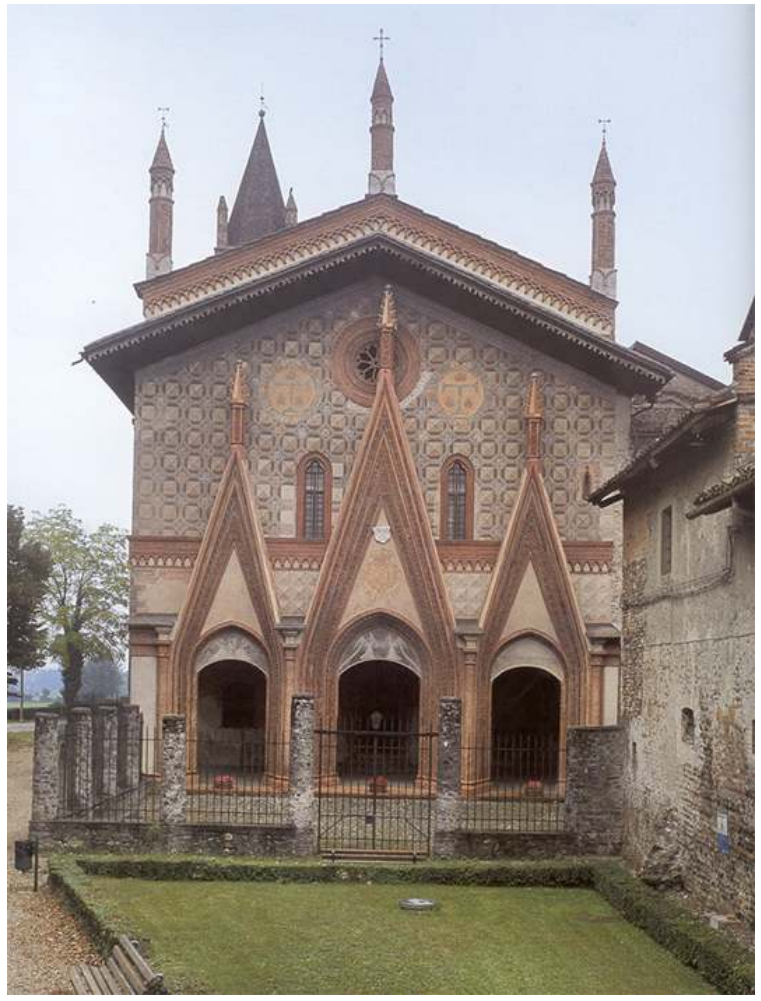

Vue de l'église de Sant'Antonio di Ranverso.

PHOT. ALFONSO SISTA. (C) ALFONSO SISTA.

L'idéologie que véhicule le néo-gothique dans les années 1820-1850 ne se départit pas d'une certaine nostalgie des temps de la chevalerie, que la Maison de Savoie aime volontiers mettre en scène: on pourrait ainsi citer l'apparat et les costumes du tournoi pour les fêtes du mariage du futur Victor-Emmanuel II en $1842^{48}$. Mais à partir de 1861, fondation du royaume d'Italie, de nostalgique, le néo-gothique italien devient avantgardiste en participant à la définition d'une architecture nationale. Car si le néoclassicisme, associé aux anciennes monarchies et à la papauté, est abandonné, le gothique du nord de l'Italie et la Renaissance renvoient au contraire au passé glorieux du temps des indépendances communales du Moyen Âge. Dans cette recherche du style national de la nouvelle Italie, le monument historique est appelé à devenir la source d'inspiration de la modernité. Un Camillo Boito ou un Alfredo D'Andrade vont contribuer à la réflexion sur les constructions anciennes par des chantiers de restauration fondateurs pour la conservation mais aussi pour l'architecture moderne. En découlent, à partir des années 1880, d'une part un historicisme officiel et grandiloquent, le style umbertino, mais aussi le néo-gothique "philologique » de Gino Coppedè qui s'inscrit dans la mouvance de l'Art nouveau, comme William Morris en Angleterre à la même époque.

L'annexion du comté de Nice à la France s'inscrit, du coup, dans la perspective d'affirmation d'une histoire de la nation française. C'est dans les traces archéologiques et monumentales que l'on tente de prouver le caractère français ou plutôt gallo-romain de Nice. Le transfert du patrimoine niçois de la Maison de Savoie à la nation française passe par des actes symboliques comme le don et non le dépôt de pièces archéologiques niçoises aux musées impériaux. En 1862, Napoléon III crée le musée des Antiquités celtiques et 
romaines à Saint-Germain-en-Laye, devenu musée des Antiquités nationales en 1879. Un important fragment de statue provenant du trophée d'Auguste est alors offert par le conseil municipal de La Turbie, sur les recommandations du ministre de l'Intérieur, à la nouvelle institution en 1869: "Ce serait une acquisition précieuse pour le musée de Saint-Germain où l'Empereur réunit tout ce qui rappelle l'administration de César et d'Auguste en Gaule ${ }^{49}$. $\gg$ La commune de Châteauneuf-de-Contes ${ }^{50}$ fait en même temps le don de deux autels votifs : « je vous prie de remercier le conseil municipal de Châteauneuf de l'heureuse pensée qu'il a eue de s'associer ainsi à une œuvre nationale ${ }^{51} »$ (fig. 13).

Figure 13

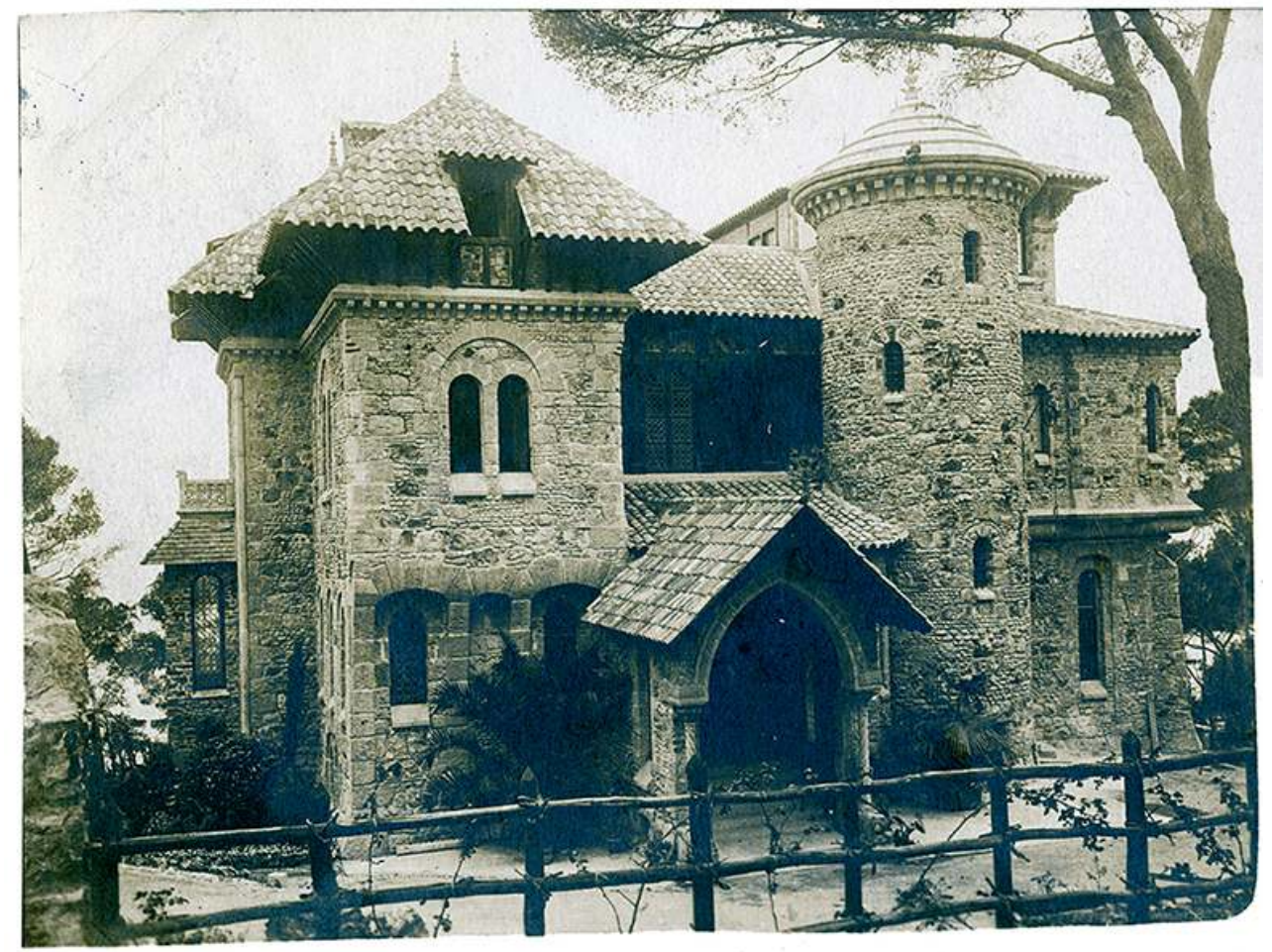

Vue de la villa Torre Clementina au Cap Martin, vers 1900.

Phot. anonyme, collection Didier Gayraud. (c) Didier Gayraud.

31 Deux sites occupent une position centrale dans l'intégration du comté dans l'histoire nationale française, on y retrouve les deux sources des Antiquités nationales, les racines celtes et la latinité. Il s'agit de Cimiez d'abord, mais présenté sous l'angle gallo-romain : en effet, à l'amphithéâtre, vestiges de la Cemenelum romaine, dans la continuité patrimoniale avec la Provence, répond l'oppidum gaulois de Bellanda, englobé dans l'enceinte du jardin des Franciscains. Dans l'écriture d'une histoire nationale, la question des origines est fondamentale puisqu'elle légitime toutes les entreprises d'expansion et toutes les possessions par le titre de premier occupant. Or, dans la France du XIX ${ }^{e}$ siècle, l'étude de la civilisation celte éveille un grand intérêt puisqu'elle confère à la France, moyennant l'assimilation des Gaulois aux ancêtres des Français, une présence largement antérieure à toutes les nations voisines sur les territoires. Pour autant, l'héritage latin est aussi revendiqué, d'où la promotion du creuset gallo-romain dont serait sortie la nation française $\mathrm{e}^{52}$. Le comté de Nice se devait donc, à partir de 1860, de porter les traces de sa celtitude. L'autre illustration de la dimension idéologique du patrimoine se retrouve chez 
les tenants d'une Nice italienne : à l'origine gauloise du comté, les irrédentistes italiens répondent par la découverte de pseudo-inscriptions étrusques sur tuile en 1872 . Le quotidien italianissime ${ }^{53}$ Il Pensiero di Nizza se fait l'écho de la découverte :

Des personnes de nos amis en excursion sur la très douce colline de Cimiez, en se promenant parmi les vestiges de l'antique capitale des Alpes-Maritimes, ont trouvé... un fragment du tuile en terre cuite portant une inscription en caractères étrusques qui correspond à ceci : MI SV.../LUCUM.../KEM...Nous n'avons pas besoin de signaler l'importance de la découverte de ce monument étrusque pour les travaux historiques se rapportant à notre pays natal... Laissons aux personnes plus qualifiées que nous le soin d'étudier cette question de manière approfondie, nous tenons à notre bureau à la disposition des chercheurs l'inscription trouvée à Cimiez. Nous ferons don avec plaisir à la bibliothèque municipale si nous étions certains qu'elle ne suive le même destin que les pierres de Saint-Martin-Lantosque [Saint-Martin-Vésubie] qui furent transportées avec peu de jugement et à grands frais au musée de Paris où elles sont exposées comme monuments celtiques (!! ${ }^{54}$.

Le deuxième monument d'importance est logiquement le trophée d'Auguste. La France y voit la preuve monumentale du tracé de la frontière entre Gaule et Italie sur la ligne de crête des Alpes, du Léman à La Turbie, Summa Alpi ${ }^{55}$ dans les sources antiques, laissant la Savoie et les Alpes-Maritimes hors de l'Italie. Le monument ne connut guère d'interventions restauratrices entre 1860 et 1905. L'engagement du maire Philippe Casimir en faveur du remontage et le mécénat d'Edward Tuck ont eu certes un rôle déterminant mais on peut néanmoins constater que la montée en puissance des restaurations du Trophée dans le sens de la restitution de l'antique est contemporaine de la poussée de l'irrédentisme transalpin qui vise à remettre en cause la frontière de $1860^{56}$ (fig. 14, fig. 15).

Figure 14

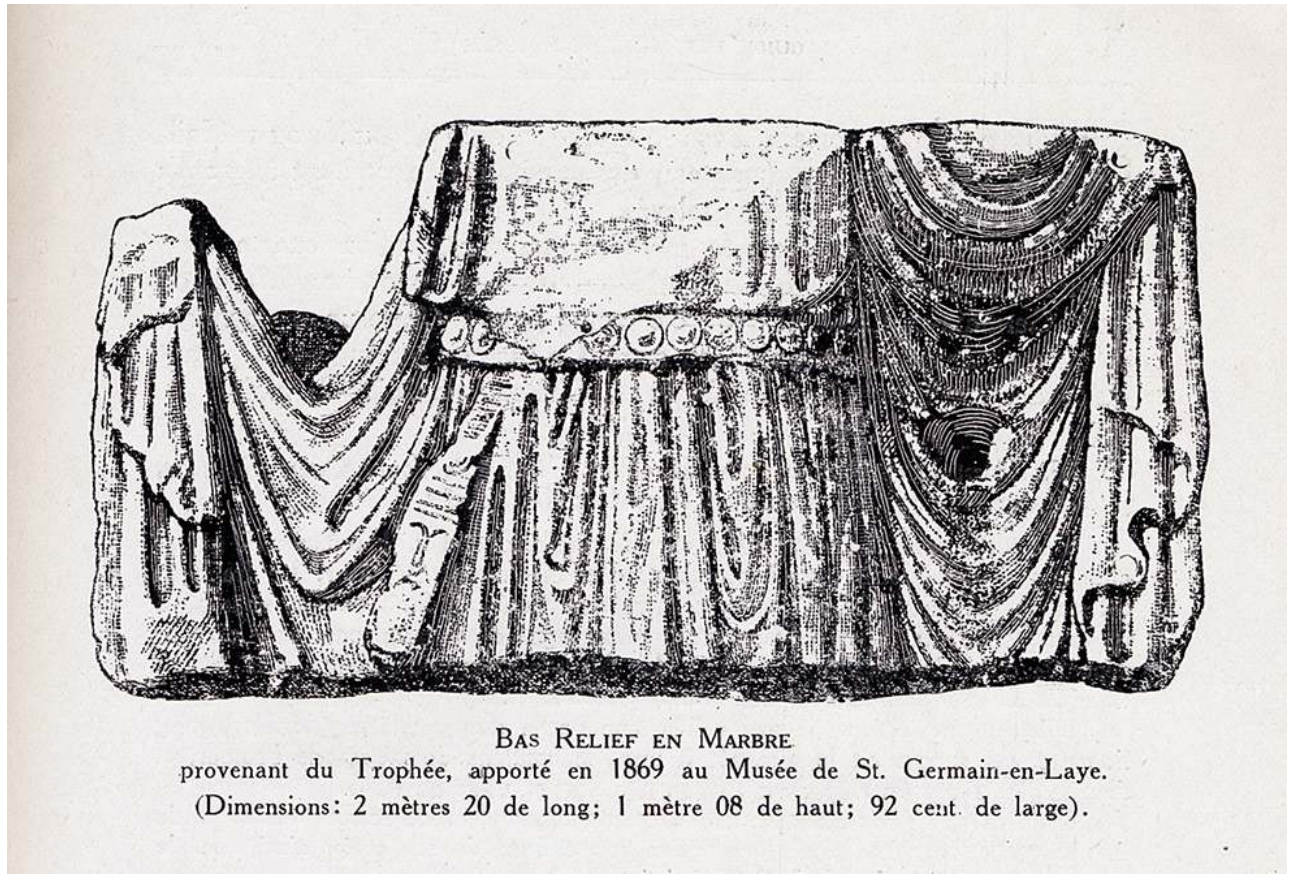

Fragment de statue provenant du trophée de La Turbie offert au musée des Antiquités nationales, Guide historique du Musée du Trophée romain, 1928. 


\section{Figure 15}

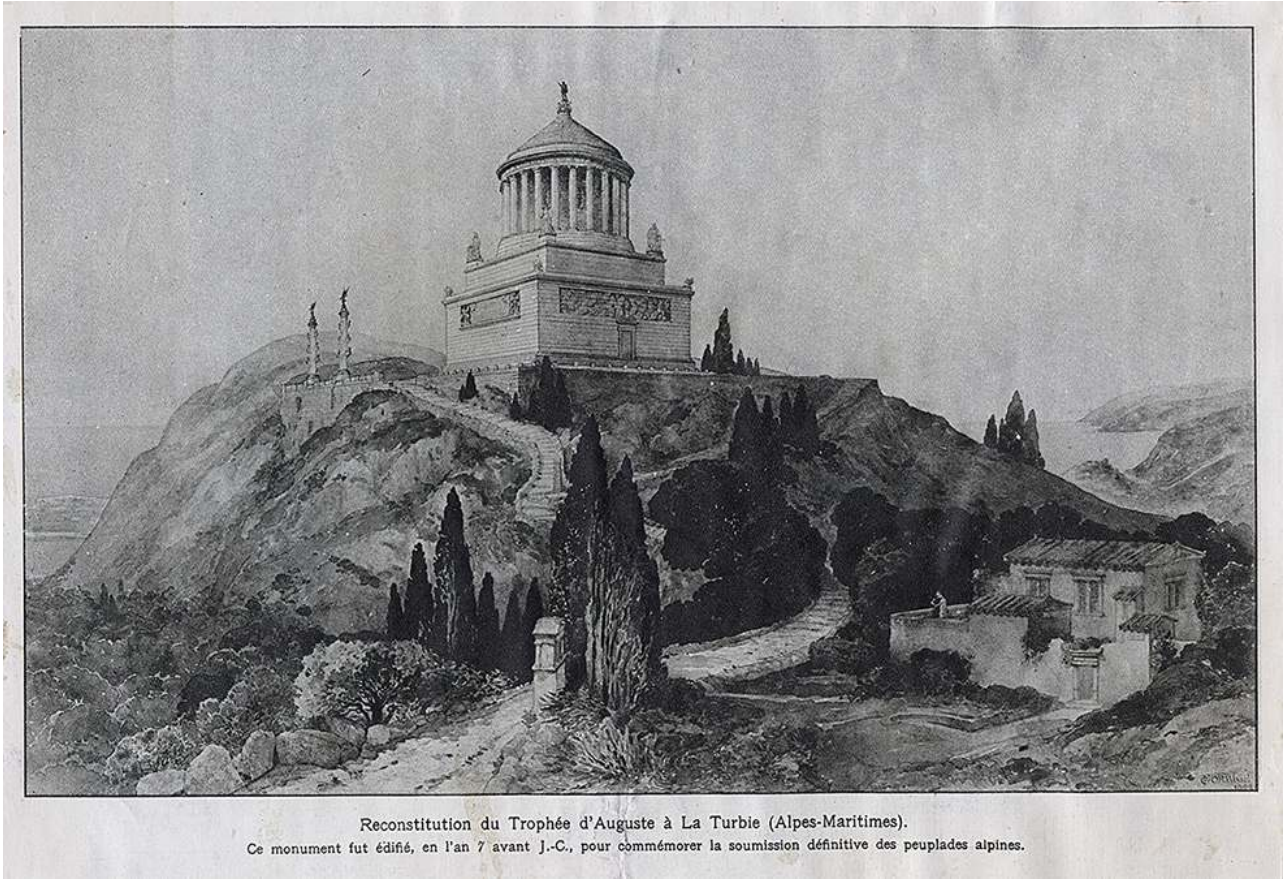

Reconstitution du trophée d'Auguste à La Turbie par Jean Camille Formigé, L'Illustration, 1920.

À l'inauguration des restaurations de La Turbie en 1934, le gouvernement fasciste répond en 1937 par l'encouragement à la fondation de l'Istituto di studi liguri par l'archéologue Nino Lamboglia. Le but avoué de l'institut sera de travailler sur la Ligurie occidentale, de la protohistoire au Moyen Âge, étendue aux Alpes-Maritimes, et sur l'italianité de l'ancien comté de Nice par l'archéologie et l'étude des toponymes ${ }^{57}$. En retrouvant sa monumentalité, le Trophée redevient le monument-signal de l'origine, qui marque la frontière des Alpes en même temps qu'il affirme la paix après la victoire (fig. 16). 


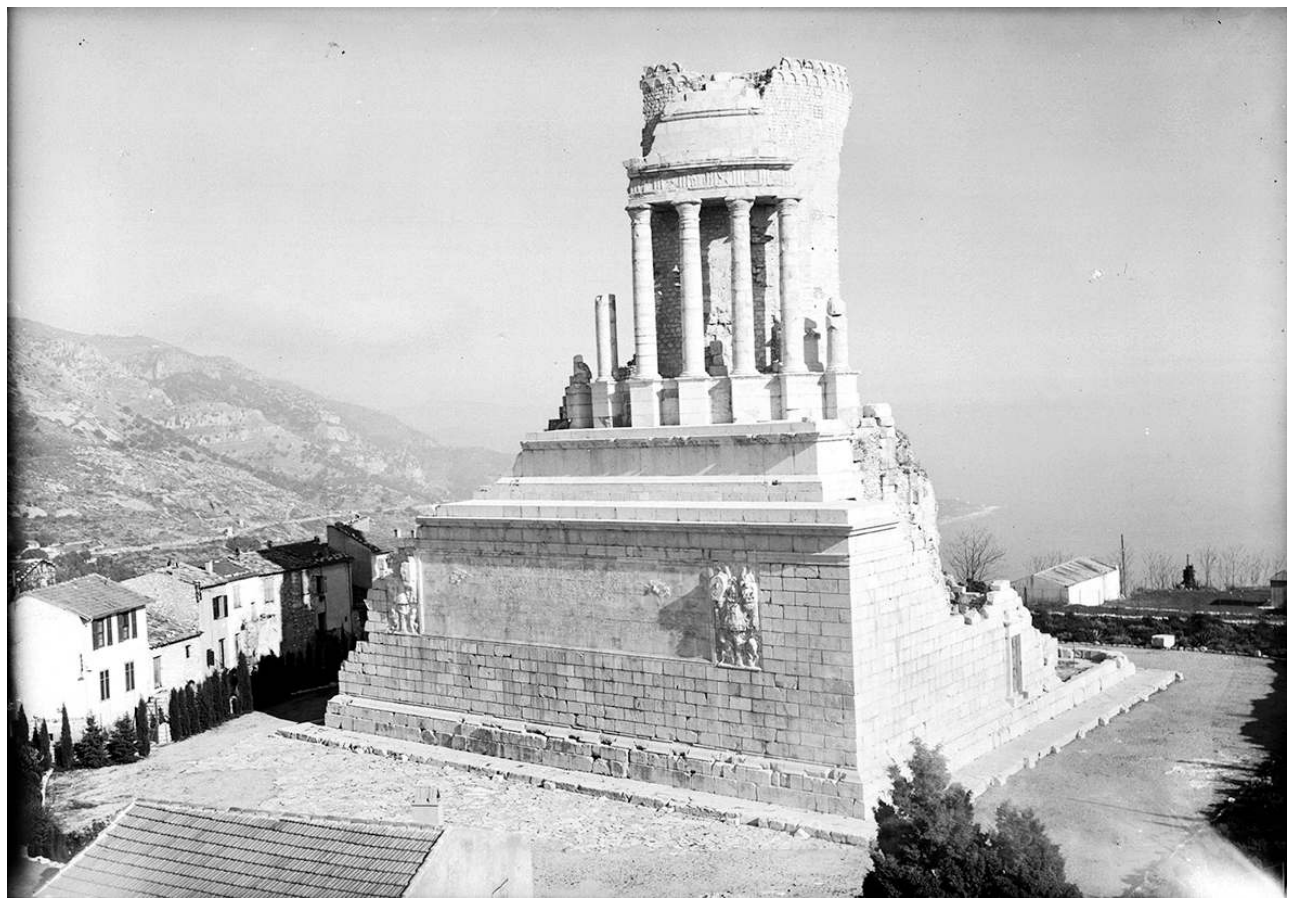

Vue du trophée des Alpes à La Turbie, vers 1920.

Phot. Jean Gilletta, Médiathèque de l'architecture et du patrimoine, GLT 3892. ( ) Ministère de la Culture (France) - Médiathèque de l'architecture et du patrimoine - diffusion RMN.

L'entrée de Nice dans l'ensemble français se situe à un moment où les États d'Europe encouragent l'écriture de leur histoire nationale. L'archéologie comme le patrimoine monumental sont promus au rang d'illustration ou de preuve. Le monument devient le signal de l'histoire nationale dans le paysage. Les transferts de souveraineté offrent un moment rare et privilégié pour observer la lecture politique du monument. C'est le cas pour le patrimoine du comté de Nice qui connait au cours du xixe siècle et jusqu'au début $\mathrm{du} \mathrm{xx}^{\mathrm{e}}$ siècle ce singulier destin de devoir affirmer tout à tour son italianité et sa francité. La question des identités culturelles s'invite donc à l'époque de la montée des nationalités puis des nationalismes en Europe.

\section{NOTES}

1. - Lettre à X..., mercredi [1861]. MÉRIMÉE, Prosper. Correspondance générale. Éd. Maurice Parturier. Toulouse/Paris : Privat/Le Divan, 1943-1972, t. X, 1956, p. 419. Charles Léon Ferdinand de Lasteyrie du Saillant : historien de l'art, il étudia les arts industriels du Moyen Âge et fut l'auteur d'une histoire de la peinture sur verre en France.

2. - La genèse des institutions de conservation en Piémont-Sardaigne est esquissée dans CERRI, Maria Grazia, BIANCOLINI, Daniela, PITTARELLO, Liliana (dir.). Alfredo d'Andrade, 
tutela e restauro. Cat. exp., Turin, Palazzo Reale, Palazzo Madama, 27 juin-27 déc. 1981. Florence : Vallechi, 1981, p. 135-136.

3. - Notons là encore le parallélisme avec la France, qui voit en 1834 la création du Comité des travaux historiques et scientifiques par Guizot.

4. - Archives départementales des Alpes-Maritimes [AD AM désormais], fonds Levrot, $6 \mathrm{~J} 26$, lettre imprimée non datée.

5. - Par décret du 13 mai 1865. Voir dans la base Mérimée : notices PA00080775 et PA00080897.

6. - C'est la construction de la nouvelle route de Cimiez qui détermina l'intervention du Génie civil en 1828. Il est signalé dans le rapport de l'ingénieur que les voitures ne peuvent se croiser « au point semi-circulaire entre la propriété du comte Nieubourg et celle du comte Garin, lieu dit la Cuve des fées ». Jusqu'au début du Xx ${ }^{\mathrm{e}}$ siècle la route de Cimiez passait à travers l'amphithéâtre, (AD AM, fonds de l'intendance générale de Nice, 1 FS 104).

7. - Voir le site : http://cths.fr/an/societe.php?id=3004 [consulté le 10/01/2019].

8. - AD AM, fonds de la préfecture, affaires culturelles, 4 T 29.

9. - L'expression est ici employée sans nuance péjorative, elle désigne dans son acception originelle la politique de brassage des conscrits de toutes les origines géographiques et sociales dans un même corps dans le service militaire, depuis la loi Jourdan et jusqu'à sa suppression. Le but avoué de l'amalgame était de forger une armée nationale et contribuer à faire de l'armée le creuset de la nation.

10. - Médiathèque de l'architecture et du patrimoine [MAP désormais], procès-verbaux de la commission des Monuments historiques, séance du 27 mars 1865 : « M. de Guilhermy, rapporteur, propose d'accueillir la demande formée par la Société des lettres, sciences et arts des Alpes-Maritimes, dans le but d'obtenir le classement des Arènes de Cimiez au nombre des monuments historiques. La commission conclut au classement proposé. » La même séance adopte le classement du trophée d'Auguste dans les mêmes conditions.

11. - Annales de la Société des lettres, sciences et arts des Alpes-Maritimes, 1865, t. I, p. 228-234 et 1877, t. IV, p. 165-172.

12. - Père de Paul, le célèbre géographe.

13. - Voir le site : http://cths.fr/an/savant.php?id=105463 [consulté le 10/01/2019].

14. - CARLONE, Auguste. Vestiges épigraphiques de la domination gréco-massaliote et de la domination romaine dans les Alpes-Maritimes. Caen : Le Blanc-Hardel, 1868.

15. - AD AM, fonds Carlone, $7 \mathrm{~J}$ 38, lettres d'Arcisse de Caumont, 1867-1869.

16. - Congrès archéologique de France, XXXIII ${ }^{e}$ session. Séances générales tenues à Senlis, Aix et Nice en 1866 par la Société française d'archéologie. Paris/Caen : Derache/Le Blanc Hardel, 1867, p. 417-478. Le palais Lascaris sera classé au titre des monuments historiques en 1945.

17. - Le Félibrige est alors à son apogée. Ce cénacle de notables provençaux, écrivains, lexicographes ou grammairiens pour la plupart, œuvre à la conservation et à la promotion de la langue provençale. Son rayonnement est considérable, à tel point que son fondateur, Frédéric Mistral, reçoit le Prix Nobel de littérature en 1905.

18. - Voir le site : http://cths.fr/an/societe.php?id=1146 [consulté le 10/01/2019].

19. - Voir dans la base Mérimée : notice PA00080795.

20. - Voir le site : http://www2.culture.gouv.fr/public/mistral/dapamer_fr [consulté le 10/01/2019].

21. - Voir dans la base Mérimée : notice PA00080747.

22. - Voir dans la base Mérimée : notice PA00080835. 
23. - Voir dans la base Mérimée : notice PA00080852.

24. - Voir dans la base Mérimée : notice PA00080779.

25. - Voir dans la base Mérimée : notice PA00080774.

26. - Voir dans la base Mérimée : notice PA00080787.

27. - Voir dans la base Mérimée : notice PA00080713.

28. - Voir dans la base Mérimée : notice PA00080880.

29. - Voir dans la base Mérimée : notice PA00080900.

30. - Voir le site : http://elec.enc.sorbonne.fr/architectes/449 [consulté le 10/01/2019].

31. - Archives nationales, dossier personnel F19/7233.

32. - AD AM, fonds de l'intendance générale de Nice, 1 FS 907, lettre du 24 juin 1857.

33. - Idem.

34. - Sommet de l'édifice, seul témoin subsistant de la période médiévale après les campagnes de restauration de Jean-Camille et Jules Formigé entre 1905 à 1933. Voir GATIER, Pierre-Antoine et GANDINI, Bénédicte. « Les restaurations du trophée de La Turbie ». Nice historique, avril-juin 2005, p. 91.

35. - BOITO, Camillo. Conserver ou restaurer, les dilemmes du patrimoine. Trad. Jean-Marc Mandosio. Besançon : les Éd. de l'imprimeur, 2000, p. 45. Sur le congrès des ingénieurs et architectes italiens de 1833 au cours duquel Boito énonce ses principes, se reporter à DI STEFANIS, Roberto. « La tutela dei beni culturali in Italia ». Restauro, juillet-août 1972, p. 17-19.

36. - Camillo Boito s'est rendu célèbre dans la littérature italienne par sa nouvelle Senso, publiée en 1883.

37. - BOITO, Camillo. Op. cit., p. 31.

38. - Boeswillwald est nommé le 29 octobre 1860. En fait, Mérimée continue d'exercer jusqu'à sa mort en 1870 une influence prépondérante sur le service. Lettre de Mérimée à Boeswillwald, Cannes le 6 janvier 1863 : «Voyez donc si les églises de Nice ou le château du Cimiez n'auraient pas besoin de votre présence ». [ "Château » a ici le sens de « monument »]. MÉRIMÉE, Prosper. Correspondance générale, éd. cit., 1957, 2e série, t. V, p. 295-297.

39. - Archives municipales de Nice, 3R 15.

40. - BOLLATI, Giulio. L'Italiano. Il carattere nazionale come storia e come invenzione. Turin : Einaudi, 1983.

41. - Protocole réservé franco-piémontais du 10 août 1860 et accord franco-piémontais sur l'établissement religieux de Hautecombe du 4 août 1862 en application du traité de Turin. Voir ADAMI, Vittorio. Storia documentata dei confini del Regno d'Italia. Rome : Stato maggiore del R. Esercito, 1919, vol. 1, p. 212-219, 345, 372-373.

42. - AD AM, fonds de l'intendance générale de Nice, 1 Fs 907, lettre de l'intendant général au ministre de l'Intérieur du 28 avril 1859. Rapport d'Hilarion Spitalieri de Cessole au roi écrit en 1827 et déposé aux Archives de la Regia, Deputazione di Storia Patria, publié sous le titre "Sur le tombeau de la duchesse Béatrix ». Nice historique, 1899, n 812, p. 148-153. Voir le site : http://www.nicehistorique.org/vwr/? nav=Index\&document=3240\&num=\&annee=1899 [consulté le 10/01/2019]. 43. - Les premiers actes symboliques du règne de Louis XVIII seront la recherche des dépouilles de la famille royale et la construction de chapelles expiatoires et de monuments commémoratifs à Paris et à Auray, où tomba la dernière armée royale en 1795.

44. - AD AM, fonds de l'intendance générale de Nice, 1 Fs 907. La collégiale de Tende est qualifiée de « parmi les plus précieux monuments des Alpes maritimes ». 
45. - Voir NERI, Maria Luisa. « Stile nazionale e identità regionale nell'architettura italiana post-unitaria ». Dans BERTELLI, Sergio (dir.). La Chioma della Vittoria. Scritti dull'identità degli Italiani dall'Unità alla seconda Repubblica. Florence : Ponte alle Grazie, 1997, p. 133-169.

46. - Voir l'ouvrage collectif BOSSAGLIA, Rossana et TERRAROLI, Valerio (dir.). Il Neogotico nel 19. e 20. secolo. Milan : Mazzotta, 1989.

47. - Cenni storici sull'antica città di Cimella e sull'attuale chiesa e convento dei Padri riformati. Nice : Tipografia Nazionale, 1858, p. 44-45.

48. - [ MANZO, Luciana, PEIRONE, Fulvio]. Pubbliche allegrezze. Feste e potere a Torino dal Cinquecento all'Ottocento. Cat. exp., Turin, 22 juin-31 oct. 2007. Turin : Archivio di Stato di Torino, 2007, p. 80-111.

49. - AD AM, fonds de la préfecture, affaires culturelles, $4 \mathrm{~T}$ 16-17.

50. - Act. Chateauneuf-Villevieille.

51. - AD AM, fonds de la préfecture, affaires culturelles, $4 \mathrm{~T} 17$, lettre du surintendant des Beaux-Arts.

52. - Il est notable que Napoléon III fut particulièrement sensible à la dimension politique de l'archéologie. Sous son règne, la France eut une politique active de fouilles en Méditerranée. Rappelons qu'il suivit les chantiers du site du Palatin à Rome et fit acheter la collection Campana. Voir : Napoléon III et l'archéologie, une politique archéologique sous le Second Empire. Actes du colloque de Compiègne, 14-15 octobre 2000. Bulletin de la Société historique de Compiègne, t. 37, 2001, et LARONDE, André, TOUBERT, Jean, LECLANT, Jean (éd.). Histoire et archéologie méditerranéennes sous Napoléon III. Actes du colloque, 8-9 octobre 2010, villa Kérylos, Beaulieu-sur-mer. Cahiers de la villa Kérylos, 2011, n 22 53. - Partisan italophile hostile à l'annexion du comté de Nice à la France.

54. - Il Pensiero di Nizza, 3 juin 1872, autres articles les 4 et 22 juin 1872.

55. - « Les plus grandes Alpes » selon l'Itinéraire d'Antonin (fin $\mathrm{III}^{\mathrm{e}}$ siècle apr. J.-C).

56. - Jusqu'en 1915, l'Italie fait partie de la Triple Entente avec l'Allemagne et l'AutricheHongrie contre la France. Le régime mussolinien, au pouvoir à partir de 1922, fait siennes les thèses irrédentistes de la droite nationaliste qui prône le retour dans l'ensemble italien de Nice et de la Savoie.

57. - L'Institut international d'études ligures, successeur de l'ancien institut, a conservé comme emblème le trophée d'Auguste.

\section{RÉSUMÉS}

Le territoire français connaît ses derniers accroissements notables dans la seconde moitié du XIX siècle, lorsqu'à l'issue de l'engagement de Napoléon III dans la guerre du Piémont contre l'Autriche, la France annexe la Savoie et le comté de Nice. Le patrimoine monumental de ces nouvelles provinces participait donc de l'histoire d'une nation étrangère avant 1860 , celle du Piémont-Sardaigne et de sa dynastie régnante, la Maison de Savoie. Le transfert de souveraineté en 1860 entraîne ce que l'on pourrait appeler un processus de francisation des monuments historiques. Le présent article s'intéresse au patrimoine du comté de Nice en décrivant les principales facettes de ce processus aux implications administratives sur le temps court, mais 
aussi scientifiques et politiques sur le temps long, depuis la décennie 1830 jusqu'aux dernières conséquences durant les années 1930, quand l'irrédentisme fasciste remit en question l'appartenance de Nice à l'ensemble français. L'installation à Nice du service français des Monuments historiques ne correspond en aucun cas à l'origine de la fonction régalienne de la protection du patrimoine. Depuis 1832, l'État piémontais a suscité la création d'une «Giunta di antichità e Belle arti» et la nomination de Carlo Promis comme premier «ispettore dei monumenti d'antichità dei reali Stati » dans les années même où la monarchie de Juillet instituait la commission des Monuments historiques et la fonction d'inspecteur. Comme la commission française à ses débuts, le dispositif du Piémont entend s'adjoindre le concours des sociétés savantes locales. Le premier recensement des monuments aboutit à une première liste de classement. Le service français prend donc le relais des premières protections. Le chantier de restauration du trophée des Alpes, à La Turbie, revêt un caractère emblématique : le parti adopté par les ingénieurs du Génie civil sarde est celui d'une stricte consolidation tandis que Viollet-leDuc et ses disciples s'engagent dans la voie de la restitution. Le changement complet de doctrine de restauration se double du changement de point de vue historique : en effet, les monuments et les sites archéologiques niçois s'intègrent avant 1860 dans la geste de la dynastie de Savoie, qui entreprend à partir de 1848 la construction de l'Italie unitaire. La question des styles revêt une dimension hautement politique en Italie du Nord, où les architectes cherchent à forger dans l'historicisme une architecture nationale pour la nouvelle Italie. L'annexion à la France fait entrer ce patrimoine dans une nouvelle histoire nationale, l'histoire de France. Un fragment antique est symboliquement donné à Napoléon III pour les collections du tout nouveau musée des Antiquités celtiques et gallo-romaines de Saint-Germain-en-Laye.

France witnessed its last significant territorial acquisitions during the second half of the nineteenth century, when, in 1860, at the end of the Austro-French Piedmontese War, Napoleon III's Empire annexed Savoy and the County of Nice. Up until that date, the heritage of these annexed provinces belonged to another nation, the Kingdom of Sardinia and its reigning dynasty, the House of Savoy. The change in sovereignty brought about what could be called a process of 'Frenchification' of the territory's historic monuments. This article focuses on the built heritage of the County of Nice, describing the main features of this process, covering shortterm administrative questions as well as longer-term scientific and political aspects between 1830 and 1930. At this last date, fascist-inspired irredentism began to question the idea that Nice should be considered a part of France. The establishment in Nice of an office of the French historic monuments administration was by no means the beginning of governmental policies to protect the region's monumental heritage. As early as 1832, the Piedmontese State had created a council of antiquities and fine arts (Giunta di antichità e Belle arti) and appointed Carlo Promis as its first inspector (Ispettore dei monumenti d'antichità dei reali Stati). This was in the same year that the government of France's July Monarchy established a historic monuments commission, together with a post of inspector. As in France, from the outset, the Piedmontese monuments administration relied considerably on the help of local scholarly societies. The first inventory of historic buildings led to an initial list of 'classified' monuments enjoying statutory protection, which the French administration took over after 1860. The restoration project on the Roman Tropaeum Alpium, the Trophy of the Alps at La Turbie, may be seen as characteristic of this continuity, but whereas Sardinian civil engineers had advocated a simple consolidation of the structure, Viollet-le-Duc and his followers preferred their perspective of restitution of the monument. This new concept in restoration also entailed some revisions in the interpretation of history. The historic monuments and archaeological sites in Nice prior to 1860 were all heritage recognised as such under the regime of the House of Savoy. A new dynamic began to affect historic monuments after 1848 when the House of Savoy became involved in the process of Italian unification. The question of style became a highly political issue in Northern Italy, where 
architects of historicist inspiration sought to forge a national architectural style suitable for the new nation. With the French annexation of the County of Nice, the heritage acquired another national history, that of France. A fragment of a monument of antiquity was symbolically given to Napoleon III for the collections of the Museum of National Antiquities at Saint-Germain-enLaye.

\section{INDEX}

Mots-clés : Nice, Alpes-Maritimes, La Turbie, Second Empire, annexion, frontière, Eugène Viollet-le-Duc, Émile Boeswillwald, Prosper Mérimée, Hector-Martin Lefuel, Savoie, Piémont, Italie, Trophée des Alpes, Arcisse de Caumont, Société française d'archéologie, Camillo Boito, nationalisme, architecture néo-gothique, Gino Coppedé

Keywords : Nice, Alpes-Maritimes department, La Turbie, Second Empire, annexion, frontier, Eugène Viollet-le-Duc, Émile Boeswillwald, Prosper Mérimée, Hector-Martin Lefuel, Savoy, Piedmont, Italy, Tropaeum Alpium, Trophy of the Alps, Arcisse de Caumont, Société française d'archéologie, Camillo Boito, nationalism, Gothic revival architecture, Gino Coppedé

\section{AUTEUR}

\section{ALAIN BOTTARO}

Conservateur du patrimoine, Responsable des Archives communales d'Antibes alain.bottaro@ville-antibes.fr 